\title{
LAS COOPERATIVAS DE VIVIENDAS EN RÉGIMEN DE CESIÓN DE USO COMO CAUCE JURÍDICO PARA LOS NUEVOS MODELOS HABITACIONALES
}

\author{
Sara Louredo Casado \\ Profa. Dra. de Derecho Mercantil \\ Investigadora post-doctoral \\ Universidad de Vigo \\ https://orcid.org/0000-0002-7847-5239
}

\section{RESUMEN}

El derecho a una vivienda digna y adecuada se recogió en la Constitución Española de 1978 y en numerosas declaraciones y cartas de derechos posteriores. Las cooperativas de viviendas, enmarcadas en la regulación del instituto cooperativo de la Constitución, se han regulado en la Ley nacional y en las autonómicas de cooperativas. La figura ha sufrido fuertemente la crisis del sector inmobiliario del año 2010 pero sigue siendo una herramienta útil para desarrollar ese derecho a poseer una vivienda. Además, son un cauce jurídico que se adapta bien a los sistemas de cesión del derecho de uso a los habitantes y a la cohabitación, dos tendencias habitacionales nuevas en nuestro país.

En este artículo queremos analizar cuál es la normativa más adecuada para regular estas iniciativas novedosas que, en otros países de Europa y América, llevan ya algunas décadas funcionando. Nos fijamos también en las experiencias españolas más recientes de cesión de uso y cohabitación que se han articulado como cooperativas.

PALABRAS CLAVE: Derecho a una vivienda digna, mercado inmobiliario, cooperativas de viviendas, cesión de uso, sistema Andel, cohousing.

CLAVES ECONLIT / ECONLIT DESCRIPTORS: H4, I3, K6, K150, K250, 018.

Cómo citar este artículo/How to cite this article: LOUREDO CASADO, S.: "Las cooperativas de viviendas en régimen de cesión de uso como cauce jurídico para los nuevos modelos habitacionales", CIRIEC-España, Revista Jurídica de Economía Social y Cooperativa, $\mathrm{n}^{\circ}$ 37, 2020, pp. 167-206. DOI: 10.7203/CIRIEC-JUR.37.17396. 


\section{THE HOUSING COOPERATIVES WITH A REGIME OF TRANSFER OF USE AS A LEGAL TOOL FOR THE NEW HOUSING PATTERNS}

\section{EXPANDED ABSTRACT}

The right to decent housing is reckoned as one of the most important social rights for citizens. It does not only imply the use of a space to live but also it has a close connection with the daily life, privacy and family organisation of the inhabitants. The importance of the right has not been disputed, being enshrined in various International Treaties and almost every Constitution in the world. However, its legal status and enforcement against public actors, in the case of Spain is not completely clear. It is recognised in article 47 of our Constitution as a right for all Spanish citizens but it is not protected by the higher guarantees of the most preserved fundamental rights.

The right to housing may be achieved by housing cooperatives, a known and ancient figure that through a philosophy of sharing -at least at a theoretical level-, reunites people with the same needs and aspirations regarding housing and with the aim of saving the maximum amount of intermediaries' costs possible. This paper wants to analyse the role that cooperative societies may have in models of housing that are new in Spain. Traditionally, in our country, housing cooperatives considered that their objective was fulfilled when the houses were built and given to their members as owners. This implied the end of the society and even of the community created through the cooperative and the appearance of a new regime based on horizontal property and Civil Law. However, nowadays, new models of inhabitation constitute an adequate solution for certain social groups: especially, the youth, the elderly and the handicapped people. These collectives, due to their special needs or way of living, do not need to be owners of a house. The alternative is not only renting but being an assignee of the use of the house that is collectively owned. This regime is well known and developed in other countries, such as the Scandinavian ones in Europe and in the United States of America.

In fact, the Andel model, which was born in Denmark and has spread to other countries such as Sweden, Finland and Germany, in a smaller scale, it is precisely a hybrid system between the ownership and the renting of a house. It consists of the common ownership of a building by the members of a housing cooperative that pay an entrance and a monthly fee to inhabit the house. This fee is lower than a monthly rent and the model has as one of its main advantages that inhabitants may remain in the house for an indefinite period of time. Apart from the Andel system, we study another recent phenomenon that is called co-housing. The idea is that the collectivity formed to build and to own the common space may be 
also looking for a common lifestyle, in terms of ecology, integration, social relationships, etc. and due to this sense of community, they integrate a co-housing community. This implies the democratic and common management of the structures built, their use in turns, a respectful organisation to achieve welfare for the ensemble. In this kind of inhabitation, cooperatives can also serve the purpose thanks to their democratic principles and social spirit. Descending to the normative regime, it is found that the Spanish legal system on cooperatives is neither an obstacle nor a help because it does not forbid the maintenance of the cooperative once the buildings are finished but it does not deeply regulate these situations. The national law -number 27/1999- and those of the Autonomic Communities in Spain are not very descriptive in the ways other than ownership in which the members of the cooperative may enjoy their houses. However, the grant of the use is mentioned in some of them and some support is found in the Civil Code. In fact, the grant of use can be achieved through a right in rem: the right to use or to usufruct. These norms will help our study but we may not loose the focus on the internal norms of the cooperative: the corporate statutes and the regulation of the intern regime as well as all the agreements adopted by the democratic organs of the society. These will constitute fundamental bases for the cooperative and the daily life of its members. They will also be of paramount importance in cases of co-housing, in which it is needed a thorough regulation of the turns, the rights of the inhabitants and the consequences of non-compliance with the internal systems.

Even if the possession of a house in ways different to ownership are not very known or popular in Spain, they started to have an increasing demand since the first years of 2010. This means that we now have some examples of communities organised on the basis of a right of use, both "simple" or in co-housing. As an example, we will analyse the norms and the requirements of access of the community of LaBorda in Catalonia. We also have observed that some municipal authorities and even the Spanish Government are now giving more support to building groups, sometimes even transferring lands to building communities for long periods of time or facilitating the access to certain subsidies, if the groups will form a co-housing community. Examples of these situations are found in the municipalities of Rivas Vaciamadrid and Atxondo and in the latest plan of housing number 9 for Spain, that we comment throughout the paper.

Our principal objective is to know if these forms that we think will be more and more used in future years can pivot over the cooperative model. We observe that the traditional real estate market based on ownership or rent is no longer an adequate solution for many people. Moreover, the economic crisis that started in 2010 showed the great amount of speculative interests that are present in this market that ultimately harm consumers. Cooperative societies, even if they have also been affected by capitalistic interests, have at their core the social welfare of members and communities. The tendencies to own in common, to share 
spaces and time and to be part of a group fit very well in the cooperative spirit from a philosophical point of view, but we also think that cooperatives are legally prepared to support these structures.

KEYWORDS: Right to an appropriate housing, real estate market, housing cooperative societies, transfer of use, Andel system, cohousing. 


\section{SUMARIO $^{1}$}

I. Introducción. II. El derecho a una vivienda digna y adecuada en la Constitución Española. III. Fórmulas de cesión de uso de las viviendas. IV. Las cooperativas de viviendas como instrumento jurídico para la cohabitación. 4.1. Regulación de las cooperativas de viviendas en España. 4.2. Objeto de una cooperativa de viviendas. 4.3. Derechos y deberes de los socios. 4.4. Régimen jurídico de una cooperativa de viviendas dedicada a la cesión del uso. V. Problemas y realidades de la cohabitación y de las cooperativas en régimen de cesión de uso. VI. Planes públicos de impulso de los nuevos modelos habitacionales. VII. Conclusiones. Bibliografía.

\section{Introducción}

Una de las necesidades básicas del ser humano es la posesión de un espacio físico en el que desarrollar de forma digna la vida diaria. Además, otros imperativos básicos están estrechamente conectados con la vivienda: la alimentación, la intimidad, la seguridad, etc. De hecho, numerosos estudios derivados de la teoría de la pirámide de MASLOW han considerado que en el primer escalón, integrado por necesidades psicológicas, debe incluirse la de shelter (literalmente refugio), que equivale a esa búsqueda de un espacio propio para habitar ${ }^{2}$. Estas ideas han fundamentado estudios sobre diseño y arquitectura que intentan incorporar al proceso de construcción de casas y apartamentos esas búsquedas psicológicas y esas motivaciones universales del ser humano.

1. El presente trabajo ha sido elaborado en el marco del Proyecto de Investigación financiado por el Ministerio de Ciencia, Innovación y Universidades: "El Derecho de la competencia y de la propiedad industrial: actualización, europeización y adaptación a la nueva economía” (2019-2022) Referencia: PGC2018-096084-B-I00, y del Proyecto de Investigación financiado por la Xunta de Galicia: "Retos para un mercado de traballo equitativo e aberto á competencia no contexto da nova economía" (2019-2021). Dereito Mercantil e do Traballo (Universidade de Vigo). DMT-Grupo con potencial de crecemento".

2. En este punto es necesario decir que Maslow no habló de la necesidad psicológica de vivienda pero el mismo autor destacó que "parece imposible así como inútil realizar una lista de necesidades fisiológicas fundamentales porque pueden ascender a casi cualquier número que uno desee, dependiendo del grado de especificidad o descripción". (vid. MASLOW, A.H.: "Teoría de las Motivaciones Humanas", Psychological Review, no 50(4), 1943, p. 6).

Sin embargo, otros psicólogos, siguiendo a Maslow, han entendido que la necesidad de refugio estaría en la base de la pirámide: vid. WAHBA, M.A. \& BRIDWELL, L.G.: "Maslow reconsidered: A review of research on the Need Hierarchy Theory", Organizational Behavior and Human Performance, vol. 15(2), abril, 1976, pp. 212-240. 
Visto lo anterior, no parece posible -y no se ha intentado- negar el carácter esencial del acceso a la vivienda. El consenso general sobre la existencia de esta aspiración humana y su configuración como un derecho puede observarse en numerosos pactos nacionales e internacionales. Así, figura en Declaraciones de Derechos, Cartas y Constituciones, vinculado a la dignidad humana y a la exigencia de un nivel de vida adecuado. Sólo por destacar algunos de ellos, a nivel internacional y regional, se ha incluido en la Declaración Universal de Derechos Humanos de 1948, en el Pacto Internacional de Derechos Sociales, Económicos y Culturales de 1966 y en la Carta Social Europea de $1961^{3}$.

Sin embargo, hemos de tornar la mirada ahora a la realidad de la vivienda a nivel internacional y particularmente en nuestro país. La crisis sufrida por el sector financiero tras la caída en bolsa de los productos hipotecarios y de los fondos de inversión inmobiliarios -a su vez, desencadenada por la quiebra de Lehman Brothers en 2008sacudió bruscamente el sector de la vivienda. Éste último constituye una verdadera cadena de producción y servicios, con numerosos intermediarios y fuertemente sometida a la especulación ${ }^{4}$. De hecho, la legalidad de algunas prácticas bancarias vinculadas a la concesión de préstamos hipotecarios ha sido puesta en entredicho y buena muestra de ello fue la anulación por el Tribunal Supremo de las cláusulas

3. El primero de estos textos trata el derecho a la vivienda directa y explícitamente en el art. 25.1: "Toda persona tiene derecho a un nivel de vida adecuado que le asegure, asi como a su familia, la salud y el bienestar, y en especial la alimentación, el vestido, la vivienda, la asistencia médica y los servicios sociales necesarios; tiene asimismo derecho a los seguros en caso de desempleo, enfermedad, invalidez, viudez, vejez y otros casos de pérdida de sus medios de subsistencia por circunstancias independientes de su voluntad".

Por su parte, el Pacto Internacional de Derechos Sociales, Económicos y Culturales lo contempla en el art. 11.1: "Los Estados Partes en el presente Pacto reconocen el derecho de toda persona a un nivel de vida adecuado para si y su familia, incluso alimentación, vestido y vivienda adecuados, y a una mejora continua de las condiciones de existencia. Los Estados Partes tomarán medidas apropiadas para asegurar la efectividad de este derecho, reconociendo a este efecto la importancia esencial de la cooperación internacional fundada en el libre consentimiento".

Finalmente, está recogido en el art. 16 de la Carta Social Europea -no así en el Convenio Europeo para la Protección de los Derechos Humanos y las Libertades Fundamentales que no lo establece de forma explícitavinculado al concepto de familia con la siguiente redacción: "Con miras a lograr las condiciones de vida indispensables para un pleno desarrollo de la familia, célula fundamental de la sociedad, las partes contratantes se comprometen a fomentar la protección económica, jurídica y social de la familia, especialmente mediante prestaciones sociales y familiares, disposiciones fiscales, apoyo a la construcción de viviendas adaptadas a las necesidades de las familias, ayudas a los recién casados o por medio de cualesquiera otras medidas adecuadas".

4. Vid. LÓPEZ LETÓN, S.: “La burbuja que embriagó a España”, Diario El País, 25 octubre, 2015. 
suelo $^{5}$, de ciertos gastos hipotecarios asignados al beneficiario del crédito y de la Cláusula Índice de Referencia de Préstamos Hipotecarios ${ }^{6}$.

La etapa postcrisis que vivimos ha supuesto una toma de conciencia sobre la necesidad de contar con una legislación sobre vivienda fuerte y aplicable en la práctica y con un control exhaustivo del mercado financiero relacionado. Además, por la mejora de la coyuntura económica, anterior al COVID-19, la concesión de créditos a los particulares comenzó a ser mayor que hace unos ańos: el Banco Europeo puso en marcha políticas de bajada de intereses y de transparencia bancaria, favoreciendo con ello a los colectivos que se vieron más afectados por las actuaciones de algunas instituciones financieras ${ }^{7}$. Por otra parte, vemos que la importancia de adquirir una vivienda en propiedad se ha relativizado: el alquiler se adapta mejor a los jóvenes, quienes experimentan una mayor movilidad laboral que sus padres y abuelos. La consecuencia de esta creciente demanda de alquileres es la inflación en los precios, agravada por el aumento exponencial de los alquileres vacacionales y turísticos. La gestión de estos arrendamientos es sencilla, gracias a plataformas virtuales como Booking o Airbnb, servicios de limpieza especializados e incluso servicios de bienvenida de los huéspedes que el propietario puede contratar. Sumado a esta operativa sencilla y organizada, los alquileres turísticos poseen las ventajas de un menor compromiso temporal con el inquilino -normalmente un máximo de tres meses- y de un aumento de ingresos para el propietario.

Frente a este difícil panorama, se escuchan voces que ponen de manifiesto la necesidad de repensar y reconducir el derecho a la vivienda y de implementar medidas concretas y efectivas para que el acceso a la misma sea real para los ciudadanos. Tradicionalmente, los Gobiernos han acudido a la construcción de Viviendas de Protección Oficial (en adelante, VPO) y al otorgamiento de subvenciones a los colectivos más desprotegidos. Sin embargo, creemos que el proceso puede articularse también a través de iniciativas privadas, en ocasiones auxiliadas por el sector público. Éste es un contexto muy propicio para devolver el protagonismo a las cooperativas de viviendas, adaptándolas a nuevas formas de habitación como la propiedad colec-

5. Nuestro TS debió rectificar su doctrina tras la sentencia del Tribunal de Justicia de la Unión Europea (en adelante, TJUE) de 13 de julio de 2016 y así lo recogió en su sentencia del Pleno de la Sala Primera de 24 de febrero de 2017.

6. Puede consultarse, para un estudio en profundidad de estas cuestiones, la página https://www.iberley.es/ temas/principales-clausulas-bancarias-declaradas-abusivas-tribunales-62615 y el artículo: ADEVA CORTÉS, C.: "Análisis de la sentencia del TJUE de 3 de marzo de 2020 (C-125/2018) sobre las cláusulas IRPH de los contratos de préstamo hipotecario para la adquisición de vivienda", Noticias Jurídicas, 9 abril, 2020.

7. En este sentido, ha resultado muy útil la consulta de la obra: CALVO VÉRGEZ, J.: Las políticas monetarias del BCE ante la crisis económica, Dykinson, Madrid, 2019, passim. 
tiva de los socios con la consiguiente cesión del derecho de uso sobre una vivienda a cada miembro; e incluso la combinación de esta cesión de uso con los sistemas de cohousing si se busca una "comunidad vital" tras la construcción. El propósito de este artículo es explorar en profundidad la normativa existente y la posible acogida de un régimen distinto a la adjudicación en propiedad por la cooperativa desde la normativa existente en la materia y con el soporte legal del Código Civil, mediante los derechos reales de uso y usufructo.

\section{El derecho a una vivienda digna y adecuada en la Constitución Española}

Nuestra Carta Magna regula en el art. 47 el derecho a la vivienda: "Todos los españoles tienen derecho a disfrutar de una vivienda digna y adecuada. Los poderes públicos promoverán las condiciones necesarias y establecerán las normas pertinentes para hacer efectivo este derecho, regulando la utilización del suelo de acuerdo con el interés general para impedir la especulación...".

En primer lugar, es una discusión muy antigua y controvertida la ubicación del precepto porque, si bien el Título I en el que se encuentra, comprende los Derechos $y$ deberes fundamentales, el Capítulo $3^{\circ}$ de dicho Título se rubrica "De los principios rectores de la politica social y económica", a los que se ha denominado "derechos aparentes". Y estos principios, según el art. 53.3 CE, "informarán la legislación positiva, la práctica judicial y la actuación de los poderes públicos. Sólo podrán ser alegados ante la Jurisdicción ordinaria de acuerdo con lo que dispongan las leyes que los desarrollen". En este sentido, sería un derecho fundamental de los menos protegidos porque no es directamente invocable ante los tribunales, no es recurrible en amparo y, en definitiva, no es un título competencial autónomo sino una directriz constitucional para los poderes públicos ${ }^{10}$. La conclusión, para una parte de la doctrina, es que no

8. Vid. JIMÉNEZ CAMPO, J.: Derechos fundamentales: concepto y garantías, Editorial Trotta, Madrid, 1999, p. 123.

9. Por el contrario, el art. 53.2 dispone una mayor garantía de ejercicio para los derechos fundamentales: "Cualquier ciudadano podrá recabar la tutela de las libertades y derechos reconocidos en el artículo 14 y la Sección primera del Capitulo segundo ante los Tribunales ordinarios por un procedimiento basado en los principios de preferencia y sumariedad y, en su caso, a través del recurso de amparo ante el Tribunal Constitucional. Este último recurso será aplicable a la objeción de conciencia reconocida en el artículo 30".

10. Vid. FERRANDO NICOLAU, E.: "El derecho a una vivienda digna y adecuada", Anuario de Filosofía del Derecho, no 9, 1992, p. 320. 
puede catalogarse siquiera de derecho subjetivo porque el mandato constitucional de promover el acceso de los ciudadanos a la vivienda se dirige a los poderes públicos ${ }^{11}$.

Sin embargo, otros autores han entendido que se trataría de un derecho subjetivo $^{12}$, lo que deriva principalmente de la dicción del precepto, la cual no trata sólo de la necesidad de actuación de los poderes públicos respecto a la vivienda sino que antes de ello afirma que "todos los españoles tienen derecho a disfrutar de una vivienda digna y adecuada ${ }^{13}$ ". Además, esta idea recibiría el respaldo de esa legislación de desarrollo a la que se refiere el art. $53 \mathrm{CE}$ y que viene constituida fundamentalmente por el Real Decreto que aprueba la Ley del Suelo: "Todos los ciudadanos tienen derecho a: Disfrutar de una vivienda digna, adecuada y accesible, concebida con arreglo al principio de diseño para todas las personas, que constituya su domicilio... (art. 5.a $\left.)^{14}\right)$ ". Con una redacción similar se recoge en la Ley gallega de Vivienda: "Las personas físicas residentes legalmente en la Comunidad Autónoma de Galicia tienen el derecho a disfrutar de una vivienda digna y adecuada, entendiendo por tal la que cumpla los requisitos técnicos y tenga la calidad necesaria para satisfacer las necesidades residenciales de las personas titulares y usuarias, conforme a lo dispuesto en el Estatuto de autonomia para Galicia y en la Constitución española (art. $3^{15}$ )".Además, la mayoría de autores que consideran que estamos ante un derecho subjetivo, entienden que es un derecho de tipo social porque su objetivo es crear las condiciones necesarias para el desarrollo libre de la personalidad y de una vida digna.

Si nos encontramos ante un derecho subjetivo, existe un correlativo deber jurídico para un sujeto, el cual viene obligado a hacer efectivo el derecho -aunque no lo sea con las garantías reforzadas del art. 53.2 CE-. En todo caso, se trata de una obligación de medios y no de resultado, en cuanto que el Estado debe emplear los cauces

11. TRUJILLO así lo entiende porque no se aplica el sistema de garantías constitucionales de los dos primeros apartados del art. 53 CE (Vid. TRUJILLO RINCÓN, M.A.: "Artículo 47". En: Comentario a la Constitución Española (dirs. PÉREZ TREMPS, P.; SAIZ ARNAIZ, A. \& coord. MONTESINOS PADILLA, C.), vol. 1 (t. 1), Tirant Lo Blanch, València, 2018, pp. 873-884).

12. Vid. GALIANA SAURA, A.: "La vivienda como objeto de estudio desde el derecho: la vivienda como derecho humano y la cátedra UNESCO sobre vivienda", Hábitat y Sociedad, no 10, noviembre, 2017, pp. 136-138.

13. En este sentido, LÓPEZ RAMÓN entiende que el art. 53.3 CE sólo descarta el reconocimiento de los principios enunciados en el Capítulo III del Título I, sin que ello afecte a los arts. 43, 44, 45 y 47, que establecen derechos (Vid. LÓPEZ RAMÓN, F.: "El derecho subjetivo a la vivienda", Revista Española de Derecho Constitucional, $\mathrm{n}^{\circ}$ 102, septiembre-diciembre, 2014, p. 59).

14. Real Decreto Legislativo 7/2015, de 30 de octubre, por el que se aprueba el texto refundido de la Ley de Suelo y Rehabilitación Urbana.

15. Ley 8/2012, de 29 de junio, de vivienda de Galicia, BOE núm. 217, de 08/09/2012. 
oportunos para asegurar la efectividad del mandato constitucional ${ }^{16}$. Como vemos, no existe una postura unánime sobre la interpretación del art. 47 CE. Sin embargo, la preocupación de este trabajo no es tanto dilucidar con claridad la catalogación de este derecho sino tener en cuenta que se trata de uno básico reconocido por numerosos textos jurídicos nacionales e internacionales y que, como mínimo, según nuestra Constitución, impone a los poderes públicos la obligación de crear las condiciones propicias para que los ciudadanos puedan satisfacer esta necesidad vital.

Pasamos a analizar el objeto del derecho, que es el disfrute de una vivienda digna y adecuada. FERRANDO NICOLAU ha afirmado que, "por vivienda, en términos generales se entiende el refugio natural, o construido por la mano del hombre, en el que éste habita de modo temporal o permanente. En cuanto a que signifique que sea digna podria entenderse que es digna aquella vivienda que da cumplimiento a las más básicas necesidades del hombre, como pueden ser una cierta privacidad-intimidad-y un elemental equipamiento ${ }^{17}$ ". Por su parte, otros autores puntualizan que no puede confundirse el derecho a gozar de una vivienda con el derecho a ser propietario de una vivienda ${ }^{18}$, ya que lo que ha interesado al constitucionalista español es proporcionar el acceso a una casa -y este acceso bien puede ser a través de un alquiler o, como veremos en este artículo, de una cesión del uso de la misma ${ }^{19}$.

En cuanto a la titularidad del derecho, el tenor literal de la Constitución es engañoso porque, cuando afirma "todos los españoles tienen derecho a disfrutar...", parece restringir este derecho a los nacionales. Sin embargo, algunos autores entienden que ha de ampliarse esta titularidad a los nacionales de otros Estados debido a la recepción, mediante el art. 10.2 CE, de la Declaración Universal de Derechos Humanos, texto que lo considera un derecho universal ${ }^{20}$. En todo caso, parece claro que habría

16. Vid. GALIANA SAURA, A., op. cit., p. 136.

17. Vid. FERRANDO NICOLAU, E., op. cit., pp. 306-307.

18. Vid. VILLANUEVA TURNES, A.: "Aproximación a la configuración jurídica del derecho a la vivienda dentro del ordenamiento jurídico español”, Opinión Jurídica, vol. 14(28), julio-diciembre, 2015, p. 83.

19. Desde un punto menos jurídico y más filosófico los autores BANHAM y OLIVER han sugerido que los espacios residenciales pueden clasificarse en tres niveles: vivienda en sentido estricto (refugio), casa y hogar. Este último es más que una estructura física y constituye una estructura social profunda. Se afirma que, si bien el de casa es un concepto denotativo, el hogar es connotativo y hace referencia a la vida que se desarrolla dentro de la casa (sueños, imaginación y memorias). Vid., en este sentido, BANHAM, R.: "A home is not a house". En: Housing and dwelling: Prespective on modern domestic architecture (dir. MILLER LANE, B.), Routledge, Nueva York, 2007, pp. 54-60; y: OLIVER, P.: Built to meet needs: Cultural issues in vernacular architecture, Architectural Press, Oxford, 2006.

20. Su universalidad teórica o genérica para los miembros de la Organización de las Naciones Unidas ha sido recientemente reconocida en los Objetivos de Desarrollo Sostenible de la Agenda 2030 a través del objetivo 
de extenderse a los nacionales de cualquier Estado miembro de la Unión Europea para evitar las discriminaciones en este espacio común ${ }^{21}$.

\section{Fórmulas de cesión de uso de las viviendas}

Cada vez más personas en nuestro país se plantean promover edificaciones en que haya una mayor experiencia de comunidad, a través de instalaciones y servicios compartidos. Esto no sólo puede suponer un ahorro de costes en la fase constructiva sino también una forma de vida posterior más acorde con su filosofía vital. Por otra parte, algunas personas no desean adquirir una vivienda en propiedad pero sí contar con una de forma duradera, sin verse afectadas por la fuerte especulación del mercado de los alquileres ${ }^{22}$. Estas demandas que nos pueden resultar nuevas y a las que hemos de dar una articulación jurídica sólida han sido ya respondidas en otros países, dando lugar a los fenómenos de la cohabitación y de la cesión de uso a los inquilinos.

En este trabajo hemos decidido centrarnos a la posesión de una vivienda en régimen de cesión de uso como alternativa a la propiedad o al alquiler. Esto se canalizará normalmente a través del recurso a una cooperativa. Por otra parte, las cooperativas y la cesión de uso a los socios pueden ser el instrumento jurídico, a su vez, para constituir una comunidad de cohabitación o cohousing, si bien ésta podría articularse también a través de un sistema tradicional de propiedad -así, los habitantes serían dueños de una vivienda y codueños de las zonas comunes-.

En primer lugar, el sistema nórdico Andel, surgido en Dinamarca en 1911, ha empleado las cooperativas de viviendas como cauce jurídico y ofrece una alternativa al tradicional mercado inmobiliario. La característica fundamental de este sistema es que los socios, colectivamente, son los propietarios de la edificación y, a su vez, son titulares de un derecho de uso sobre una de las viviendas. Esto implica que el habitante no puede adquirir la propiedad, si bien tiene más derechos que un inquilino

número 11: "Conseguir que las ciudades y los asentamientos humanos sean inclusivos, seguros, resilientes y sostenibles".

21. Vid. VILLANUEVA TURNES, A., op. cit., p. 83.

22. Es cierto, como ha indicado MERINO HERNÁNDEZ, que en España el modelo tradicional de vivienda se basa en la propiedad por diferentes razones como la falta de regulación (desarrollo) del contenido de la cesión de uso y de la vivienda en general, la mentalidad espańola sobre la propiedad, un funcionamiento de las cooperativas basado en una lógica de empresas constructoras y no de empresas de gestión de un parque de viviendas, entre otras (Vid. MERINO HERNÁNDEZ, S.: "La cooperativa de viviendas como administradora de bienes comunes", Gizarte Ekonomiaren Euskal Aldizkaria/Revista Vasca de Economía Social, no 9, 2013, p. 105). Sin embargo, desde 2013 aproximadamente asistimos a la opción por diferentes formas habitacionales, acompańadas de algunos impulsos municipales que comentamos ut infra. 
convencional en régimen de alquiler -entre ellos, la duración indefinida del derecho de uso-.

Es precisamente la condición de miembro de la cooperativa el origen de este derecho, que se adquiere pagando una cuota de entrada proporcional a la superficie de la vivienda y será devuelta en caso de abandono de la cooperativa; y se mantiene pagando una cuota mensual asequible para cubrir el coste de la deuda contraída por la promoción (adquisición de la tierra y construcción o rehabilitación) así como para mantener el edificio y la cooperativa. Además, el derecho puede ser legado, vendido y arrendado -sería una especie de subarrendamiento-. El precio de venta es acordado por la cooperativa como conjunto y tiene en cuenta las mejoras y los costes de mantenimiento que sean atribuibles al inquilino anterior ${ }^{23}$.

El modelo parte de la iniciativa privada, si bien puede recibir apoyo de los gobiernos bajo la forma de cesiones de uso del suelo en el que construyen, como ha ocurrido en algunos países del centro y norte de Europa durante décadas ${ }^{24}$. El sistema Andel es distinto del cohousing porque no se orienta a construir una comunidad vital de habitantes pero tiene también una idea de colectividad que se canaliza a través del asociacionismo cooperativo.

La autoconstrucción y la cesión de uso son también populares en Alemania, sobre todo en Berlín, donde los futuros habitantes se organizan a través de los llamados Baugruppen o grupos de construcción, que acuden a un arquitecto al que piden que adapte la vivienda a sus necesidades y deseos particulares. Normalmente, este tipo de edificios van a contar con áreas comunes y con un jardín de acceso público ${ }^{25}$.

En segundo lugar, el cohousing o la cohabitación hace referencia en sentido estricto a la efectiva organización de la vida de una comunidad de propietarios que comparten más zonas y servicios que en una propiedad horizontal tradicional. Es necesario destacar la dificultad para ofrecer un concepto válido de cohousing debido a la variedad y heterogeneidad de situaciones que se encuentran amparadas en el mismo. Aun así, intentaremos aproximarnos etimológica e históricamente a este fenómeno. Cohousing es un término anglosajón formado por la partícula co-, que hace referencia

23. Vid. CABRÉ ROMANS, E. \& ANDRÉS GALLART, A.: "Learning from each other: Catalonia meets Denmark", Housing Europe (EU blog), 16 junio, 2014.

24. BRUUN apunta que, al contrario que en otros Estados de bienestar europeos, la vivienda social en Dinamarca no había estado tradicionalmente en manos del Estado ni de sus agencias sino de cooperativas y asociaciones sin ánimo de lucro que intentaban encontrar un equilibrio entre el mercado y el Estado y preservar un bien común de propiedad colectiva (Vid. BRUUN, M.H.: "The financialization of Danish cooperatives and the debasement of a collective housing good", Critique of Anthropology, vol. 38(2), junio, 2018, p. 5).

25. Vid. RING, K.: "Reinventing density: how baugruppen are pioneering the self-made city", The Conversation, 22 noviembre, 2016. 
a algo compartido, y housing, que es alojamiento o vivienda. Por ello, se incluyen en el término varias formas de habitar con las siguientes características: la posesión de algunas instalaciones comunes, el control directo y democrático en la gestión de dicha comunidad y el desarrollo de un estilo de vida colaborativo ${ }^{26}$.

El origen del modelo se encuentra ligado a los países escandinavos. En este sentido, Suecia y Dinamarca fueron los primeros en desarrollar comunidades cohabitacionales efectivas a lo largo del S. XX ${ }^{27}$. Más recientemente la idea cobró fuerza en EEUU de la mano de los arquitectos MC CAMANT y DURRETT, que escribieron de forma pragmática y técnica sobre este tipo de viviendas en el año $1988^{28}$. En este sentido, en el cohousing norteamericano se ha observado un mayor preocupación medioambiental y homogeneidad en la composición social de las comunidades ${ }^{29}$.

Por su parte, en Francia, destacan algunos ejemplos concretos de cohousing, como el efectuado en la ciudad de Grenoble, si bien no son tan numerosos como en otros países. Destaca el fenómeno en algunas áreas rurales porque se vincula a la creación de espacios comunes para guardar y usar por turnos materiales relacionados con el cultivo de la tierra y la artesanía, entre otras actividades ${ }^{30}$. Esto prueba que existen muy diversas formas de cohabitar -podríamos decir que casi tantas como comuni-

26. Vid. MCCAMANT, K. \& DURRETT, C.: Cohousing: A contemporary approach to housing ourselves, Ten Speed Press, Berkeley, 1989.

Algunos autores han destacado también la incidencia que esta vida en común de los miembros habitantes tiene en el tiempo vital, en el sentido, de que se crea una cantidad de tiempo que deja de ser privado y pasa a ser común, lo que supone un desafío para las normas culturales de privacidad y posesión individual (Vid. JARVIS, H.: "Saving Space, sharing time: integrated infrastructures of daily life in cohousing", Environment and Planning A: Economy and Space, vol. 43(3), marzo, 2011, p. 563).

27. En el segundo país dos autores publicaron sendos artículos que dieron gran difusión a la cohabitación: GRAAE, "Los hijos deberían tener cien padres", de 1967; y GUDMAND-HOYER, "El eslabón perdido entre Utopía y la anticuada casa unifamiliar", de 1968. Además, el Gobierno danés apoyó económica y socialmente este tipo de viviendas casi desde su aparición y hasta la actualidad. Por su parte, en Suecia tuvieron buena acogida las teorías de la habitación colaborativa por sus beneficios para las mujeres trabajadoras por fomentar una mejor conciliación de la vida laboral y familiar. Así, se crearon viviendas donde los propietarios o arrendatarios del apartamento contaban con espacios comunes de cocina y guardería.

28. También en Estados Unidos, algunos pensadores del siglo XIX pusieron de manifiesto las bondades de la habitación comunitaria, si bien desde un punto de vista romántico y en muchas ocasiones poco realista. Sí había existido una propuesta colaborativa en la ciudad de Nueva York, en los años 20, donde se había construido una cooperativa de apartamentos.

29. Vid. DURANTE, C.: "Active citizenship in Italian cohousing: a preliminary reflection", Everyday Life in the Segmented City (eds. PERRONE, C., MANELLA, G. \& TRIPODI, L.), vol. 11, Emerald Group Publishing Limited, Bingley, 2011, pp. 307-333.

30. Vid. BRESSON, S. \& DENÈFLE, S.: "Diversity of self-managed cohousing initiatives in France", Urban Research \& Practice, vol. 8(1), 2015, pp. 5-16. 
dades- pero consideramos que pueden reducirse básicamente a tres: el senior cohousing ${ }^{31}$, el cohousing integrado y el eco-housing. El primero se caracteriza por la edad de sus habitantes, normalmente pertenecientes a la tercera edad. La necesidad de viviendas adaptadas, la búsqueda de alternativas a las residencias geriátricas y los efectos beneficiosos de compartir esta etapa vital con gente que se encuentra en la misma situación son las principales razones para optar por sistemas de vida en común. Por su parte, el cohousing integrado se diferencia del anterior en que agrupa a personas de distintas edades: personas mayores y familias con niños, entre otras. Finalmente, en el eco-housing lo determinante es que los habitantes tengan una preocupación especial por cuestiones medioambientales: el reciclaje, la creación de compostaje, el autoabastecimiento agrícola en la medida de lo posible, etc. Como características sostenibles de estas comunidades se observan, entre otras, la eficiencia energética. Desde un punto de vista social y humano, combaten el creciente proceso de aislamiento individual y la pérdida de bienestar recíproco que ha implicado una sociedad cada vez más atomizada en hogares de una o pocas personas ${ }^{32}$.

El cohousing se ha organizado a nivel jurídico mayoritariamente a través de las cooperativas de viviendas, tanto para la fase de construcción y diseño de las edificaciones como para la posterior comunidad de vida. Cada grupo de habitantes es un pequeño mundo y las reglas internas son fundamentales para ordenar aspectos como las aportaciones necesarias y los sistemas de devolución de las mismas en caso de baja y el aprovechamiento de los espacios compartidos. De nuevo, puede resultar útil en estos casos que la cooperativa retenga la propiedad en su conjunto y que se ceda a cada socio el uso de su espacio. Ahora bien, cesión de uso y cohabitación no son equivalentes, el cohousing puede articularse a partir de la adjudicación de la propiedad por la cooperativa.

31. Hemos tratado en profundidad la cohabitación sénior en: LOUREDO CASADO, S.: "El 'senior cohousing' en España a través del recurso a las cooperativas de viviendas”. En: Economía colaborativa y Derecho: aspectos civiles, mercantiles y laborales (dirs. CARRIL VÁZQUEZ, X.M., GARCÍA PÉREZ, R. \& LÓPEZ SUÁREZ, M.A.), Editorial Aranzadi, Cizur Menor, 2019, pp. 219-237.

32. Vid. JARVIS, H., op. cit., p. 574. 


\section{Las cooperativas de viviendas como instrumento jurídico para la cohabitación}

\subsection{Regulación de las cooperativas de viviendas en Espańa}

Las cooperativas forman parte del fenómeno más amplio de la economía social y están inspiradas por unos valores y principios que denotan -al menos en un plano ideal- una mayor preocupación por el bienestar humano y social que por la percepción de un beneficio económico. En este sentido, los principios cooperativos, tal y como están vigentes según la Alianza Cooperativa Internacional, son la adhesión libre y voluntaria; el control democrático por los socios; la participación económica de los socios; la autonomía e independencia; la educación, formación e información; la cooperación entre cooperativas; y la preocupación por la comunidad.

Nuestra Constitución hace una mención genérica a las cooperativas en el art. 129.2, que se encuentra en el Título VII sobre Economía y Hacienda: "Los poderes públicos promoverán eficazmente las diversas formas de participación en la empresa y fomentarán, mediante una legislación adecuada, las sociedades cooperativas... 33 ”.

Al amparo de este precepto constitucional se promulgó la Ley 27/1999 de Cooperativas $\left(\mathrm{LC}^{34}\right)$. Esta ley es la base para la regulación del cooperativismo en nuestro país. Sin embargo, no se trata del único texto en España puesto que las Comunidades Autónomas han dictado sus propias leyes en la materia, haciendo uso del art. 149.3 $\mathrm{CE}^{35}$. Por ello, la ley nacional ha quedado relegada a una posición de marco jurídico y de instrumento integrador de lagunas. Para efectuar un análisis más completo sobre el objeto de este artículo, haremos referencia a algunos preceptos de las Leyes de Cooperativas de las Comunidades gallega $\left(\mathrm{LCG}^{36}\right)$ y andaluza $\left(\mathrm{LCA}^{37}\right)$. Concreta-

33. La Constitución portuguesa menciona ya a las cooperativas de viviendas en el artículo dedicado al derecho a la vivienda: "1. Todos tienen derecho, para sí mismos y para su familia, a una vivienda de dimensión adecuada, en condiciones de higiene y comodidad y que preserve la intimidad personal y la privacidad familiar.

2. Para asegurar el derecho a la vivienda, incumbe al Estado: (...)

c) Estimular la construcción privada, con subordinación al interés general, y el acceso a una vivienda propia o alquilada;

d) Incentivar y apoyar las iniciativas de las comunidades locales y de las poblaciones, tendentes a resolver los respectivos problemas habitacionales y a fomentar la creación de cooperativas de vivienda y autoconstrucción" (art. 65; traducción de la autora).

34. BOE núm. 170, de 17 de julio de 1999.

35. Art. 149.3 CE: "Las materias no atribuidas expresamente al Estado por esta Constitución podrán corresponder a las Comunidades Autónomas, en virtud de sus respectivos Estatutos".

36. Ley 5/1998, de 18 de diciembre, BOE núm. 72, de 25/03/1999.

37. Ley 14/2011, de 23 de diciembre, BOE núm. 17, de 20/01/2012. 
mente, la regulación de las cooperativas de viviendas se encuentra en los artículos 89 a 92 de la LC, 120 a 123 de la LCG y 97 y 98 de la LCA.

No queremos finalizar este apartado sin hacer una precisión de tipo práctico. Hemos destacado el lado social del fenómeno cooperativo, que es el que consideramos que se encuentra tanto en el origen como en la esencia de la institución. La confianza que genera esta forma social que procura velar por la solidaridad y la gestión democrática entre sus miembros, ha llevado a emplear la cooperativa en muchos sectores económicos, desde la agricultura a la prestación de servicios a los consumidores. Y las viviendas no son una excepción. Sin embargo, esto no implica que en algunas ocasiones se haga un uso "más capitalista" de la institución presidido por la búsqueda de un beneficio fiscal o del ahorro de costes, sin apenas distinguirse de otras formas de asociacionismo. Esto ha afectado particularmente a la reputación del cooperativismo de viviendas que, en épocas pasadas, fue empleado por algunos promotores inmobiliarios con la única intención de obtener un tipo social ventajoso. Sin negar la existencia de situaciones en las que se ha hecho un uso incorrecto o incluso fraudulento de las cooperativas, queremos centrarnos en casos en que, por una arraigada idea de comunidad en la propiedad, estas sociedades se convierten en auténticos instrumentos para cumplir los objetivos de la Economía Social.

\subsection{Objeto de una cooperativa de viviendas}

El art. 89.1 de la LC establece el objeto de las cooperativas de viviendas con la siguiente redacción: "Las cooperativas de viviendas asocian a personas físicas que precisen alojamiento y/o locales para si y las personas que con ellas convivan". A esto se añade la posibilidad de "procurar edificaciones e instalaciones complementarias para el uso de viviendas y locales de los socios, la conservación y administración de las viviendas y locales, elementos, zonas o edificaciones comunes y la creación y suministros de servicios complementarios, así como la rehabilitación de viviendas, locales y edificaciones e instalaciones complementarias". Los apartados 2 y 4 del mismo precepto indican las actividades que la sociedad puede desarrollar tanto para hacer efectivo este objeto como para adquirir rendimientos de las edificaciones construidas: adquirir, parcelar y desarrollar los trabajos necesarios; y enajenar o arrendar a terceros, no socios, los locales comerciales y las instalaciones complementarias de su propiedad.

Interesa, a efectos de este artículo, el apartado 3 que hace referencia a las posibilidades de adjudicación de las viviendas a los socios: "La propiedad o el uso y disfrute de las viviendas y locales podrán ser adjudicados o cedidos a los socios mediante cualquier título admitido en derecho. Cuando la cooperativa retenga la propiedad de las 
Las cooperativas de viviendas en régimen de cesión de uso como cauce jurídico para...

(pp. 167-206)

viviendas o locales, los Estatutos establecerán las normas a que ha de ajustarse tanto su uso y disfrute por los socios, como los demás derechos y obligaciones de éstos y de la cooperativa, pudiendo prever y regular la posibilidad de cesión o permuta del derecho de uso $y$ disfrute de la vivienda o local con socios de otras cooperativas de viviendas que tengan establecida la misma modalidad". Como vemos, la norma permite que la adjudicación no sea únicamente a título de propiedad sino de cualquier otro contemplado en nuestra legislación civil y, en todo caso, permite a la cooperativa retener la propiedad de las viviendas, lo que implica transmitir a los socios bajo la forma de un alquiler, un usufructo o cualquier otra cesión del uso del derecho.

Las legislaciones autonómicas no varían mucho de este planteamiento general pero sí ponemos de manifiesto ahora algunas particularidades relevantes. En primer lugar, destaco la legislación gallega, no sólo por ser la de aplicación en mi autonomía sino también porque es más detallada en aspectos que la legislación española omite. En el art. 120.4 establece que "las cooperativas de viviendas administrarán y gestionarán de forma directa la promoción de viviendas y locales no pudiendo ceder tal gestión a terceras personas mediante ningún título, salvo acuerdo de la asamblea general adoptado por los dos tercios de los votos presentes y representados, sin perjuicio de la posibilidad de requerir a personas expertas externas para cuestiones puntuales". Además, se hace una referencia específica a la duración de la cooperativa en el apartado 3: "la cooperativa se constituirá por tiempo determinado fijado estatutariamente, debiendo disolverse por cumplimiento de su objeto social finalizada la ejecución de la promoción y entrega de viviendas y locales $y$, en todo caso, a los seis años desde la fecha de otorgamiento de la licencia municipal de primera ocupación, salvo que la cooperativa retuviera la propiedad o que la normativa específica de aplicación estableciese un plazo superior ${ }^{38}$ ". Luego, si parece que la regla general es la disolución de la cooperativa cuando se adjudican las viviendas en propiedad, existe la posibilidad de que sea la cooperativa quien la retenga y, por tanto, no se disuelva cuando ha finalizado la fase constructiva.

Por su parte, nos fijamos en la LCA por su mayor especificidad tanto en los sistemas de cesión de uso de la vivienda como por la amplia enumeración de algunos usos posibles de ésta. En primer lugar, el art. 97.3 se refiere a la cesión de uso y al

38. Más completa en este punto que la ley gallega aunque menos específica que la andaluza, es la Ley de Cooperativas de Euskadi (Ley 11/2019 de 20 de diciembre) que, en su art. 118.3, estipula el régimen de cesión de uso a los cooperativistas: "Cuando la cooperativa promueva o adquiera un conjunto de viviendas y locales, todo ello como inmueble único, para su cesión a las personas socias, el conjunto inmobiliario será propiedad de la cooperativa en pleno dominio u otro derecho, con carácter indefinido o de duración determinada si así se prevé en los estatutos.

En tal caso, las personas socias cooperadoras ostentarán un derecho de uso sobre la vivienda y locales que les sean adjudicados por la cooperativa conforme a sus estatutos y normas de organización interna que regularán sus derechos y obligaciones". 
alquiler con opción a compra: "Los estatutos sociales podrán prever, mediante cualquier título admitido en derecho, la transmisión de la propiedad de las viviendas, locales y construcciones complementarias a los socios y socias, o, simplemente, la cesión de su uso $y$ disfrute, manteniéndose la titularidad de la propiedad por parte de la sociedad cooperativa, incluido el alquiler con opción a compra. Ambos regímenes podrán coexistir en una misma sociedad cooperativa, de establecerse estatutariamente". En segundo lugar, el apartado 4 del mismo artículo establece: "El derecho sobre la vivienda podrá adquirirse con carácter de residencia habitual; para descanso o vacaciones; como residencia de personas mayores, discapacitadas o dependientes; para facilitar el acceso de jóvenes $y / o$ grupos de población con especiales dificultades de acceso a la vivienda, o para cualquier otro de análogas características, con los limites establecidos en la presente ley, sin perjuicio de lo dispuesto en la legislación sobre vivienda protegida". Nos parece que la profusión del artículo materializa la idea de promover el derecho a la vivienda del precepto constitucional ${ }^{39}$.

Finalizamos este apartado dedicado al objeto de las sociedades cooperativas haciendo referencia a la debatida cuestión de la presencia o ausencia de un ánimo de lucro. En general, en las cooperativas no se habla de beneficios directamente repartibles entre los socios -al estilo de las sociedades capitalistas-, si bien pueden existir retornos distribuibles. Esas plusvalías se destinarán a formar reservas para la sociedad cooperativa, como la del fondo de formación y educación de los miembros. Hay autores que defienden una visión amplia del concepto de "ánimo de lucro", incluyendo en éste el ahorro de costes que obtienen los socios al acudir a la forma cooperativa ${ }^{40}$. Sin embargo, a nuestro juicio, no puede hablarse de un verdadero ánimo de lucro porque el ahorro de costes no puede equipararse al retorno obtenido en las sociedades capitalistas $^{41}$, el cual constituye un importante incentivo para la entrada de nuevos miembros. Al contrario, como sabemos, las cooperativas no emplean el criterio del

39. Recordemos en este punto que es de las legislaciones que se han reformado más recientemente, por lo que abre ya la puerta a nuevos modelos habitacionales.

40. Vid. MILÁ RAFEL, R.: Promoción inmobiliaria, Autopromoción y Cooperativas de Viviendas, Editorial Aranzadi, Cizur Menor, 2014, p. 183.

41. ETXEZARRETA y MERINO descartan el ánimo de lucro en las cooperativas de viviendas aunque el beneficio obtenido por los socios sea el ahorro de los costes vinculados al promotor inmobiliario (Vid. ETXEZARRETA ETXARRI, A. \& MERINO HERNÁNDEZ, S.: "Las cooperativas de vivienda como alternativa al problema de la vivienda en la actual crisis económica", REVESCO. Revista de Estudios Cooperativos, $\mathrm{n}^{\circ} 113$, 2014, p. 104).

Los mismos autores han destacado que la cooperativa de viviendas puede considerarse un subtipo especial de las de consumidores porque comparte con ellas un rasgo fundamental: los socios son los destinatarios de los bienes o servicios que éstas suministran (ibid. p. 105). Por su parte, la autoconstrucción implica que la cooperativa tiene rasgos también del tipo propio de trabajo asociado (ibid. p. 108). 
capital de cada socio ni en relación a los derechos políticos de los miembros ni para cuantificar el retorno distribuible a cada uno, en su caso. La pauta para este reparto es la de la actividad cooperativizada.

\subsection{Derechos y deberes de los socios}

Pasamos ahora a considerar, desde una perspectiva legislativa general, cuáles son los principales derechos y obligaciones de las partes de la relación en las cooperativas con cesión de uso de la vivienda a los socios. Como se ha visto, el objeto social de la sociedad es procurar las viviendas a los socios. Ésta es su principal obligación y el elemento fundamental de la actividad cooperativizada; los miembros tienen el correlativo derecho de obtener una vivienda al finalizar la promoción. Para lo último, los socios deben realizar aportaciones al capital que son de dos tipos: aportaciones para ser socio y aportaciones para llevar a cabo la edificación y obtener una vivienda. La constitución de una cooperativa, como la de otras sociedades, requiere la financiación de las actividades de la sociedad desde el inicio -aportaciones al capital social-. Estas entregas iniciales, en el caso de las cooperativas de viviendas, son testimoniales en comparación las cantidades ingresadas a cuenta que los miembros realizan a lo largo de la vida de la sociedad para cubrir los gastos asociados a la construcción y aquellos otros que son necesarios para poder habitar la vivienda, como la expedición de licencias ${ }^{42}$.

Normalmente la cooperativa actuará por cuenta de los socios en la actividad de promoción y contratará a una empresa constructora, la cual ejecutará materialmente la obra. Hay distintas teorías sobre la naturaleza de esta actividad cooperativizada. Para LAMBEA RUEDA, una de las más adecuadas es la de la interposición gestora de la sociedad, esto implica que la cooperativa ostenta, respecto al socio, una representación indirecta frente a terceros que intervienen en la construcción ${ }^{43}$. La

42. Lambea Rueda entiende que estas aportaciones ingresan temporalmente en un régimen de copropiedad y nunca directamente en el patrimonio de la cooperativa (Vid. LAMBEA RUEDA, A., Cooperativas de Viviendas, Editorial Comares, Granada, 2007, p. 186).

MERINO HERNÁNDEZ comparte la idea y habla de recursos propios de la cooperativa -por ejemplo, para las cantidades relativas al capital social- y recursos ajenos -las cantidades entregadas a cuenta de la construcción-. El autor entiende que "cualquier cambio de estos criterios supondría modificar la imagen fiel de la contabilidad de la cooperativa y alteraciones en las ratios de tesorería, solvencia financiera, endeudamiento..." (Vid. MERINO HERNÁNDEZ, S., "Cooperativas de viviendas". En: Tratado de Derecho de las Sociedades Cooperativas (dir. PEINADO GRACIA, J.I. \& coord. VÁZQUEZ RUANO, T.), vol. 2, Tirant lo Blanch, València, 2019, pp. 1641-1642).

43. LAMBEA RUEDA, A.: Cooperativas..., p. 185. 
cooperativa será quien actúe como promotora y, cuando la construcción finalice, las viviendas y locales se pondrán a disposición de ésta por el constructor ${ }^{44}$. A continuación, la cooperativa adjudicará el uso o propiedad de lo construido a los socios. En el momento en que se transmite la propiedad y no quedan ya edificaciones ni locales en posesión de la cooperativa, el objeto social se cumple y aquélla se disuelve pero esta consecuencia no es automática ya que la legislación abre la puerta a la pervivencia de la sociedad cooperativa cuando no se cede a los socios la propiedad de las viviendas sino únicamente su uso.

Esta fórmula habitacional que parece una excepción a la regla general de adjudicación en propiedad en nuestro país, lleva ya algunas décadas funcionando en Dinamarca, Suecia, Noruega y EEUU. En el caso, por tanto, de que se ceda el uso a los socios, no se dividiría totalmente la comunidad existente porque, si bien puede individualizarse la cuota de uso de cada socio, la propiedad del conjunto del edificio pertenece a la cooperativa, de forma similar al derecho de usufructo, que implica que, sobre una cosa, existe un titular que es propietario y otro que es usuario del bien.

\subsection{Régimen jurídico de una cooperativa de viviendas dedicada a la cesión del uso}

\subsubsection{El apoyo normativo del Código Civil: los derechos de uso y usufructo}

Tras exponer ut supra el modelo Andel y el fenómeno del cohousing en otros países, hemos de preguntarnos si es jurídicamente posible en España y cuál sería su regulación. En lo que se refiere a su posible existencia, venimos de concluir que, tanto la legislación nacional como las autonómicas, permiten a las cooperativas de viviendas mantener la propiedad de las mismas y ceder el uso a los socios por cualquier medio admitido en Derecho.

En cuanto a la regulación, dado que estamos ante un derecho de uso, como facultad separada de la propiedad sobre un bien, siempre podemos acudir al Código Civil, que recoge el derecho de propiedad y los derechos reales. El derecho de uso, regulado en los arts. 523 y ss. del CC, se apoya, a su vez, en el derecho de usufructo, más profuso en relación a las obligaciones y derechos de los intervinientes en el con-

44. Según la Ley de Ordenación de la Edificación española (Ley 38/1999, de 5 de noviembre, BOE núm. 266, de 06/11/1999) es promotor "cualquier persona, fisica o jurídica, pública o privada, que, individual o colectivamente, decide, impulsa, programa y financia, con recursos propios o ajenos, las obras de edificación para si o para su posterior enajenación, entrega o cesión a terceros bajo cualquier título" (art. 9). Por su parte, el constructor "es el agente que asume, contractualmente ante el promotor, el compromiso de ejecutar con medios humanos y materiales, propios o ajenos, las obras o parte de ellas con sujeción al proyecto y al contrato" (art. 11). 
trato que le da origen. Tanto el derecho de uso como el de usufructo se caracterizan por la temporalidad y la imposibilidad de disfrutar del bien a título de propietario -en nuestro caso, la vivienda-. Estas notas determinan la relación jurídica entre el miembro y la cooperativa cuando la fase de promoción ha terminado.

El derecho de uso permite emplear una cosa -en nuestro caso la vivienda- y disfrutarla directamente. Tradicionalmente el derecho de uso se distinguía con mayor claridad del de usufructo porque la facultad de disfrute se encontraba más limitada para el usuario. Sin embargo, en la actualidad el derecho ha pasado a ser "un pequeño usufructo", en el que el beneficiario puede percibir una parte de los frutos para uso cotidiano ${ }^{45 / 46}$. Por su parte, el usufructo "da derecho a disfrutar los bienes ajenos con la obligación de conservar su forma y sustancia, a no ser que el título de su constitución o la ley autoricen otra $\cos a^{47}$. . A pesar de la regulación pormenorizada que contiene el CC, se observa más profusión en los derechos y obligaciones del usufructuario que en los del nudo propietario, en lo que se refiere al contenido del contrato ${ }^{48}$. En todo caso, ambos derechos reales pueden constituirse de forma voluntaria, por acuerdo de

45. Hemos de entender que las necesidades del usuario no son un concepto cerrado y unitario sino que se modulan en función de la posición social y las circunstancias del caso. Igualmente, en la "familia" se pueden integrar personas que no reúnen estrictamente esta condición -invitados y empleados-. Algunos autores han considerado el derecho de uso como un usufructo limitado (Vid. ALBALADEJO, M.: Curso de Derecho Civil Español. Derecho de bienes, J.M. Bosch Editor, Barcelona, 1982, pp. 339 y ss.).

46. Vid. DíEZ-PICAZO, L. \& GULLÓN, A.: Sistema de Derecho Civil, vol. III (t. 2), Editorial Tecnos, Madrid, 2012, p. 68.

47. Art. 467 CC.

48. Así, como derechos del primero se contemplan el aprovechamiento del bien -con la correspondiente percepción de los frutos y la posibilidad de realizar las necesarias mejoras-, la posesión del bien -que nunca dará acceso al dominio por usucapión, debido a que su título no es de propiedad-, y las posibilidades de arrendar y enajenar su derecho. Sus obligaciones integran tres tipos distintos, según el momento temporal en que surgen. En primer lugar, las anteriores al disfrute son fundamentalmente las de hacer un inventario del bien que recibe y prestar una fianza, si bien puede eximirse de la prestación de la misma según lo dispuesto en el art. 493 CC. Una vez constituido el usufructo, el usufructuario debe conservar la cosa y mantenerla en buen estado, así como informar al nudo propietario de cualquier acto lesivo para el bien. Y la principal obligación posterior al usufructo es la de devolver la cosa, en nuestro caso, la vivienda.

COSSÍO entendía que nos encontramos ante dos derechos (nuda propiedad y usufructo) sobre un mismo objeto, y de ello se origina una especial forma de comunidad y relaciones entre los mismos en un plano jurídico-real y jurídico-personal. En el primero, los respectivos derechos aparecen como autónomos y sustantivos. En el plano jurídico personal, en cambio, hay que reconocer entre ellos una recíproca interdependencia, derivada de la limitación que para el contenido de ambos supone la necesidad de respetar la sustancia y forma de la cosa sobre la que recaen (Vid. DÍEZ-PICAZO, L. \& GULLÓN, A., op. cit., p. 43). 
las partes y éste sería el supuesto aplicable a las cooperativas de viviendas en régimen de cesión de uso ${ }^{49}$.

A pesar de la orientación que pueda ofrecer el CC, esta norma sólo entra en juego en defecto de la regulación que contiene el título constitutivo del negocio que da origen al derecho de uso -por ejemplo, un contrato ${ }^{50}$-. Esta preponderancia del título constitutivo tiene como consecuencia que no se puedan estudiar los derechos de uso y usufructo separadamente del negocio jurídico en el que tienen su origen, que en nuestro caso es la pertenencia a una cooperativa. Todos los cambios que las partes están habilitadas para introducir en los aspectos que no pertenecen al ius cogens de estos institutos son consecuencia de la posibilidad de que estos derechos surjan por negocios jurídicos inter vivos y del principio de autonomía de la voluntad. En este sentido, ALBALADEJO considera que pueden existir obligaciones y derechos entre el propietario y el usufructuario que no vienen dispuestos por la Ley para el tipo normal sino que son establecidos por los constituyentes y ni siquiera en atención al carácter de parte y contraparte del usufructo sino con base en el negocio constitutivo ${ }^{51}$. LAMBEA RUEDA considera que tras el título constitutivo no habría de acudirse al CC sino a las normas legales específicas sobre cooperativas y sólo en tercer y cuarto puesto, las normas sobre los derechos de uso y de usufructo ${ }^{52}$. Sin embargo, hemos observado que las normas legales sobre cooperativas, tanto nacional como autonómicas, poco se refieren al derecho de uso, más que a través de una fórmula genérica que lo considera una de las formas posibles de transmisión de la vivienda a los socios por parte de la cooperativa.

Por lo expuesto, aunque el usufructo exige normalmente la prestación de fianza, creemos que puede prescindirse de esta obligación en los casos de constitución de la cooperativa. Por otra parte, si bien no es habitual exigir el abono de una renta por parte del usufructuario o usuario, este deber del socio cooperativo habitante será lógico en los casos en los que la cooperativa como conjunto conserve la propiedad de lo construido y el inquilino se encuentre en una situación de posesión similar a

49. Art. 468 CC: "El usufructo se constituye por la ley, por la voluntad de los particulares manifestada en actos entre vivos o en última voluntad, y por prescripción".

Puede verse un estudio completo acerca de la constitución voluntaria del usufructo en el Capítulo II de la obra: PEREÑA VICENTE, M.: La constitución voluntaria del usufructo, Dykinson, Madrid, 2005.

50. Art. 528 CC: "Las disposiciones establecidas para el usufructo son aplicables a los derechos de uso y habitación, en cuanto no se opongan a lo ordenado en el presente capitulo".

51. Vid. ALBALADEJO, M., op. cit., p. 302.

52. Vid. LAMBEA RUEDA, A.: "Cooperativas de viviendas en Espańa: modelos de adjudicación”. En: VII Congreso Internacional RULESCOOP, 5 septiembre, 2012, p. 15. 
la de un arrendatario ${ }^{53}$. Igualmente, el usufructo permite al usufructuario enajenar o arrendar el bien que le ha sido cedido pero esto podría suponer, para la cooperativa, una alteración en su formación democrática y un aumento de la influencia de los intereses individuales de algunos socios sobre el interés común del conjunto. Por ello, pueden imponerse restricciones al ejercicio de estas facultades de disposición por parte de los habitantes.

Algunos autores han destacado puntos en los que el sistema de cesión de uso de una vivienda y el derecho real de usufructo no encajan bien. En primer lugar, desde un punto de vista más teórico, en la cooperativa no se daría una ajenidad real entre usufructuario (socios) y nudo propietario (cooperativa), al ser los cooperativistas miembros de la sociedad. Esto podría salvarse, sin embargo, entendiendo que la personalidad de los miembros y de la persona jurídica es diferente y que la ajenidad se ve cumplida al menos en el plano formal. En segundo lugar, en general, se faculta al usufructuario a aprovechar por sí la cosa o disponer de su derecho, lo que no parece compatible con el caso cooperativo. Finalmente, el nudo propietario tiene la idea de que su propiedad será plena en algún momento del futuro pero no ocurre así en las cooperativas de viviendas con régimen de usufructuarios ${ }^{54}$. En efecto, concordamos con que la adaptación del usufructo a esta situación jurídica no es, en absoluto, perfecta pero se trata de uno de los derechos reales que más se relacionan con la situación jurídica de los usuarios -no propietarios-, especialmente si su edad es avanzada de una vivienda en cesión de uso.

\subsubsection{La normativa de los estatutos y pactos internos. Cuestiones relevantes}

Es precisamente la relevancia que adquiere la autonomía de la voluntad y la autogestión de la cooperativa las que hacen que los estatutos y el reglamento de régimen interno, que siempre son documentos de gran importancia para estas sociedades, lo sean aún más en cooperativas de viviendas en las que existirá una posterior cohabitación o una propiedad de la construcción compartida por todos los socios. El éxito de las normas dependerá de su flexibilidad para adaptarse a las situaciones o conflictos que vayan surgiendo en la vida diaria y, a la vez, de su grado de detalle para ofrecer pautas útiles y métodos de solución concretos. Algunas cuestiones especialmente

53. La renta normalmente comprende los gastos de mantenimiento de la construcción y la devolución del crédito que una entidad bancaria concede para efectuar la construcción.

54. Vid. LAMBEA RUEDA, A.: “Cooperativas...”, pp. 19-20. 
problemáticas y relevantes son el uso y aprovechamiento de los servicios comunes, la baja del socio y el régimen de cesión de la vivienda a terceros.

Respecto al aprovechamiento de las instalaciones, la regulación interna adoptará una forma similar a la regulación con la que cuentan las comunidades de propietarios en situación de propiedad horizontal, con las particularidades propias de la constitución de un derecho de uso y de la posesión de un mayor número de zonas comunes. Si estamos ante un cohousing, será imprescindible que se establezcan con claridad la composición de los grupos y órganos de trabajo y la elección de sus miembros. Además, cabe pensar que surgirán con frecuencia situaciones de conflicto o fricciones que deben ser resueltas preferiblemente por medios autocompositivos, para que los habitantes recurran al diálogo que exige una convivencia tan estrecha.

En cuanto a la baja del socio, ha de recordarse el principio cooperativo fundamental de puertas abiertas, que implica la libre entrada y salida de los miembros de la cooperativa. Dicho esto, el principio puede convivir legítimamente con la imposición de ciertas limitaciones a los socios, como plazos de preaviso que debe cumplir quien quiera causar baja. Ello tiene su razón de ser en la descapitalización que supondría para la cooperativa la baja de los socios, especialmente si se produce una acumulación en un breve periodo de tiempo. Estas limitaciones han de ser proporcionadas y no deben imponer cargas excesivas a los socios.

Una cuestión muy importante relacionada con la baja es la liquidación de las cuentas entre la cooperativa y el socio y la recuperación de cantidades por parte de éste. El capital social -que recordemos que, en las cooperativas de viviendas, se considera testimonial respecto a las aportaciones a cuenta de la construcción- será reintegrado en todo caso al socio por la cooperativa porque es la cantidad que convertía al socio en miembro de la comunidad y, tras la baja, deja de ostentarse esta participación. Además, el socio que aportó capital para edificar ha de ser reembolsado de esas otras inversiones a cuenta de la construcción. Para algunos autores, estas devoluciones se verían facilitadas por la consideración de esas cantidades, por la cooperativa, como aportaciones al capital social ${ }^{55}$.

En este punto se plantea también la duda acerca de si el socio tendría que buscar a un sustituto para que asumiese su cuota de participación. La legislación da preferencia en la asunción a la cooperativa, lo cual resulta lógico si pensamos que son sus órganos los que deben llevar una lista de socios expectantes -esto es, un registro de

55. Agradezco en este punto a la Profa. Gemma Fajardo una aclaración particular en la materia que tuvo lugar durante el X Coloquio Ibérico organizado por el Ciriec y la Fundación Inatel en Lisboa el 16 y 17 de noviembre de 2019. Sin embargo, hemos visto que otros autores no comparten esta opinión y piensan que esta consideración podría desnaturalizar el sistema financiero estructural de la cooperativa ( $\mathrm{Vid}$. nota a pie 42 de este trabajo). 
personas que desean entrar en la sociedad-. Así lo establece el art. 92.1 LC: "En las cooperativas de viviendas, el socio que pretendiera transmitir «inter vivos» sus derechos sobre la vivienda o local, antes de haber transcurrido cinco años u otro plazo superior fijado por los Estatutos (...), deberá ponerlos a disposición de la cooperativa, la cual los ofrecerá a los solicitantes de admisión como socios por orden de antigüedad ${ }^{56}$. La primacía de la cooperativa se refuerza con la concesión de un derecho de retracto -en el apartado 2 del mismo artículo- para el caso de que el socio enajenase su cuota a un tercero sin respetar el proceso mencionado ${ }^{57}$.

También relacionada con la baja se encuentra la regulación de la transmisión o cesión de la cuota de participación de cada socio y, con ello, de su derecho de uso. Como veremos, las cuotas de participación se han convertido en algunos países, en tiempos de especulación financiera, en un instrumento o activo de inversión cuya negociación puede perjudicar muy negativamente a la sociedad y al resto de miembros de la cooperativa. En este sentido, el modelo escandinavo denominado "Andel" que comentamos ut supra concede, desde hace unos años, a los miembros gran libertad para disponer de su derecho ${ }^{58}$. Sin embargo, consideramos que algunas restricciones podrían estar plenamente justificadas para mantener el carácter intuitu personae de las cooperativas de habitación y el respeto a los principios cooperativos y al espíritu de la economía social. En este sentido, como mínimo, han de cumplirse los requisitos estipulados por la cooperativa para ser socio. Estas limitaciones, que deben ser proporcionadas, quedarían amparadas por la libre autonomía de la voluntad.

En relación a la organización diaria de las comunidades habitacionales, especialmente aquéllas en las que se produce una cohabitación, las experiencias de países como Estados Unidos muestran que puede ser útil emplear un calendario común a efectos, por ejemplo, de conocer qué huéspedes -familiares o amigos de otros miembros- necesitarán alojarse en la comunidad y en qué periodos o de utilizar los servicios por turnos. Igualmente, las nuevas tecnologías como, por ejemplo, los chats o

56. Con similar redacción figura en el art. 121.3 LCG. La LCA se refiere también a una prelación en la transmisión, si bien con un proceso un poco diferente: "La transmisión de derechos sobre las viviendas, locales o construcciones por parte de las personas socias, asi como las operaciones con terceras personas, se someterán a un régimen de prelación que contemplará, de crearse por la consejería de la Junta de Andalucía competente en materia de sociedades cooperativas, el listado de personas solicitantes de vivienda" (art. 98.i)).

57. Sensu contrario, si la transmisión se produce fuera de los plazos indicados en el artículo, hemos de entender que -salvo disposición distinta de los estatutos sociales- el socio es libre de transmitir a terceros, sin que exista una prioridad de la cooperativa.

58. Se trata de los riesgos que lleva aparejada la financialización de las cuotas cooperativas, comentada en el apartado $\mathrm{V}$ del presente trabajo. 
los programas para planificar comidas son de gran ayuda para la gestión diaria ${ }^{59}$. En el fondo, estos usos, pueden constituir auténticas normas de funcionamiento de la comunidad creada.

\subsubsection{Algunos ejemplos de cohousing y cooperativas de cesión de uso en España}

En nuestro país asistimos, desde el año 2010 aproximadamente, al nacimiento de modelos habitacionales que no pivotan sobre la propiedad de la vivienda sino sobre la cesión de uso y la formación de comunidades. Han aparecido algunas iniciativas de cohousing pero también fórmulas más sencillas en las que una cooperativa construye o remodela un edificio o espacio, conservando la propiedad, y cediendo el uso durante un tiempo ilimitado a los socios. Con estas fórmulas se intenta evitar la especulación más feroz del mercado inmobiliario y garantizar a los habitantes una continuidad temporal en el uso de la vivienda.

Nos fijamos en dos agrupaciones concretas. En primer lugar, la asociación Jubilares, integrada por cooperativas de senior cohousing, que se presenta en su página web del siguiente modo: "Se trata ante todo de un conjunto de personas cuyo objetivo es envejecer bien, con autonomia y dignidad, y que entienden que el mejor entorno es una buena vecindad. Por lo tanto, la prioridad es la formación de la comunidad, (...) Estos métodos se han desarrollado según un modelo de "senior cohousing", (...). Este tipo de comunidades suele agrupar entre 15 y 30 viviendas privadas en torno a un edificio o planta de zonas comunes para uso comunitario. Legalmente se estructuran como Cooperativas de cesión de uso o de derecho de superficie".

Esta asociación se integra por cinco cooperativas que se encuentran en distintas fases de constitución -algunas en proceso constructivo y otras en el estado de formación y preparación anterior-. Una de ellas, la denominada "Cohabita Rivas" ha recibido apoyo del Ayuntamiento de esta localidad mediante la cesión de suelo público y el diseño de las viviendas, como veremos ut infra.

En el apartado de preguntas frecuentes en la página web de la cooperativa madrileña se refieren a aspectos importantes como la amortización del suelo y la posibilidad de venta de las viviendas. En relación al primer aspecto, se insiste en que las parcelas se cederán a los adjudicatarios. Esta cesión se realiza por un período de 75 años, a cambio de un canon social. Al final del periodo el edificio pasa a ser de propiedad municipal. También se aclara que, como en cualquier cooperativa, las aportaciones reembolsables del capital se recuperan al salir de ella, con arreglo a las 
normas establecidas en la ley y los estatutos. En lo que se refiere a la posibilidad de vender la vivienda, la respuesta es que no existe tal opción. La cooperativa, en base a unos estatutos y un reglamento de régimen interno, es la que decidirá qué personas entran en régimen de cesión de uso. Sin embargo, es posible desistir del derecho de uso y recuperar la inversión inicial.

En segundo lugar, la cooperativa catalana LaBorda se encuentra rehabilitando el recinto fabril barcelonés de Can Batlló para construir viviendas de las que se asignará un derecho de uso a los socios y en las que existirán algunos espacios en común. Además de facilitar sus estatutos en la página web ${ }^{60}$, explican aspectos relevantes como la financiación y viabilidad del proyecto y las cuotas concretas de los socios ${ }^{61}$.

Nos detenemos en las materias que consideramos más relevantes y los estatutos tratan con mayor detalle. En primer lugar, el art. 9 desarrolla el régimen de uso y establece que tendrá una duración indefinida y que sus únicas causas de extinción serán la baja de la persona socia y la expulsión de ésta ${ }^{62}$. De la baja se ocupan los arts. 12 y ss. y entre las causas justificadas se encuentran: la imposibilidad de un socio para hacer frente a los pagos pendientes de liquidar a pesar de la necesidad de la vivienda, debido a una modificación de las circunstancias personales del socio destinatario (art. 13.1.b)); y la inconformidad del socio usuario con un incremento de los costes

60. Pueden consultarse los estatutos en la siguiente dirección:

http://www.laborda.coop/es/proyecto/documentos/

61. Se establece en relación a la financiación que "se realizará básicamente a partir de las aportaciones de capital de las personas socias habitantes, aquellas que puedan hacer las socias colaboradoras, y lo que se pide a entidades de las finanzas solidarias y transformadoras. Esta última financiación se articula a partir de participaciones en capital, emisión de titulos participativos y un préstamo a la inversión.

La cooperativa fundamenta su viabilidad en el ingreso de cuotas asociadas al uso de las viviendas. Como cooperativa sin ánimo de lucro y de iniciativa social, la cooperativa está obligada estatutariamente a destinar el conjunto de sus excedentes a favorecer, a través del modelo cooperativo de cesión de uso, la posibilidad de acceder a una vivienda digna, eficiente y asequible".

Y en relación a las cuotas exigibles a los socios: "El precio de obra gira entorno a los 2.400.000€. Hay una cuota inicial para socios y socias habitantes de $200 €$. Esta sirve para convertirse en socio, socia de la cooperativa.

En segundo término, hay que hacer una aportación al capital social de $15.000 €$ por cada una de las unidades de convivencia o viviendas de la cooperativa. Este importe es retornable en caso de cambio de domicilio. El capital social conjunto de la cooperativa sirve como a capital inicial para pedir el crédito que hará posible la construcción. Finalmente, cuando el edificio esté construido, se pagará una mensualidad. El precio todavía no está estipulado. Este importe servirá para devolver el crédito y pagar los gastos. No será retornable”.

62. Destaca también la previsión del art. 9.1 en relación a la extinción del derecho de uso de los terrenos -que es independiente de la cesión de uso de la vivienda-: "En caso de que la cesión de terrenos en los que la Cooperativa ha promovido las viviendas extinguiera, y la Cooperativa perdiera la titularidad sobre el edificio o las viviendas, el derecho de uso adquirido por las personas socias no quedará extinguido, por lo que la Cooperativa deberá hacer todo lo necesario para asegurar la efectividad del derecho sobre una nueva vivienda". 
totales de la vivienda como consecuencia de acuerdos de mejoras tomados por la Asamblea General (art. 13.1.c)).

En segundo lugar, la transmisión de los derechos se recoge en el art. 11, que establece en primer lugar que "la condición de socia o socio destinatario de una cesión de uso sólo se puede transmitir entre personas que forman parte de las unidades de convivencia ${ }^{63}$ " si bien la Asamblea General podrá realizar valoraciones de casos excepcionales que presente el Consejo Rector ${ }^{64}$. En esta línea, se permite la transmisión de las aportaciones al capital social -mínimas, obligatorias y voluntarias- pero sólo a otras personas socias, tanto por actos entre vivos como por actos sucesorios. La consecuencia de la transmisión total de la aportación es la baja con la consiguiente extinción del derecho de uso sobre la vivienda. En el caso de que no sea posible transmitir la aportación a un socio, el que desea vender ha de causar baja -calificada como voluntaria-. Finalmente, se establece que, en caso de muerte, "los herederos o herederas no reciben en herencia la condición de socio o socia ni el derecho de uso sobre la vivienda, sino sólo el derecho a recuperar el capital social aportado a la Cooperativa para la persona difunta. Si quieren ser socias o socios deberán cumplir los requisitos para serlo y asi lo deberán solicitar al Consejo Rector de la Cooperativa, de acuerdo con lo previsto en estos Estatutos".

Vemos que la normativa fundamental de las iniciativas habitacionales articuladas en torno a las cooperativas de viviendas es de tipo privado e interno. Las comunidades son las que, sin incumplir las pocas disposiciones de ius cogens que prescriben la legislación cooperativa y el CC, dispondrán las obligaciones y los derechos de los usuarios y de la cooperativa que más se adapten a sus necesidades y objetivos.

\section{Problemas y realidades de la cohabitación y de las cooperativas en régimen de cesión de uso}

La búsqueda de soluciones habitacionales más sociales y menos sometidas a la especulación inmobiliaria que estudiamos en el presente artículo no carece de problemas. La propia figura de la sociedad cooperativa, a pesar de estar inspirada por unos valores de comunidad y solidaridad, puede verse afectada por malos usos y por la influencia de intereses particulares poco acordes con dichos valores. En este sentido, no podemos olvidar que, en los años inmediatamente anteriores a la crisis, las cooperativas se vieron afectadas por la especulación como cualquier otra sociedad. Los 
precios de las viviendas en las cooperativas aumentaron y la adhesión a la sociedad se articuló a través de formularios estandarizados.

La crisis económica repercutió de forma importante en la financiación concedida por las entidades bancarias, especialmente para la construcción y la adquisición de viviendas. Las valoraciones de éstas, que habían servido como base de los créditos hipotecarios, bajaron bruscamente en poco tiempo. Algunas promociones se paralizaron por falta de recursos económicos externos y de los propios socios. Además, existía una gran inseguridad sobre la conveniencia de efectuar ingresos para construir a una sociedad que quizás no podría acabar la obra. Y las posibilidades de salida de esta situación no eran muchas ya que, si bien el primer principio cooperativo es el de puertas abiertas, la avalancha de bajas y la inexistencia de sustitutos de los socios que salían resultaron muy difíciles de gestionar para las cooperativas endeudadas. Esto implicó un desprestigio general de las cooperativas de viviendas y una ruptura con la economía social. Ahora bien, no todos estos problemas son atribuibles a la mala praxis de los socios sino también a la difícil coyuntura económica de esos años.

Creemos que es justo separar los fallos propios de la institución, que han de intentar corregirse con la legislación y que se producen en un contexto económico "normal", y otros que derivan de una coyuntura de crisis - externos a la cooperativa e independientes de este tipo social- y cuya desaparición puede ser tan difícil como "luchar contra los elementos". Es cierto que existirían mecanismos correctores ex post que derivan fundamentalmente de la posibilidad de los órganos administrativos de desmantelar falsas cooperativas si cuentan con indicios suficientes de que su funcionamiento real no se ajusta a la forma social. Sin embargo, estos controles, articulados sobre el proceso de descalificación de la cooperativa tienen lugar a posteriori ${ }^{65}$. Ex ante, hemos de confiar en que los fundadores de una cooperativa no utilizarán desnaturalizadamente esta forma social. Ello implica, en el fondo, creer que se regirán por el principio de la buena fe en la constitución de la coopearativa.

Nos detenemos en los problemas asociados a las cuotas de participación propias de los sistemas de cesión del uso. En Dinamarca, donde comenzó el sistema Andel, asistieron en los años 2001 y siguientes a un proceso de "financialización" de las cuotas cooperativas individuales de los socios, consecuencia de la implementación de

65. La descalificación de la cooperativa se regula en el art. 116 de la LC y en este precepto, entre las causas que dan lugar a este proceso, se encuentra "la comisión de infracciones muy graves de normas imperativas o prohibitivas de la presente Ley" (apartado 1, letra b)). Creemos que se podría basar la descalificación en el art. 1 de la Ley sobre el concepto de la cooperativa, su funcionamiento democrático y el respeto a los principios de la ACI.

En la LCG ya se prevé como una de las causas de descalificación que se produzca "la pérdida o el incumplimiento de los requisitos necesarios para la calificación de la sociedad como cooperativa" (art. 141.1.c)). 
algunas políticas neoliberales. En concreto, desde principios del S. XXI, el Gobierno danés permitió que los miembros de comunidades de propiedad horizontal transformasen sus comunidades en cooperativas y compraran acciones individuales en éstas -solicitando una hipoteca individual diferente e independiente de la que suscribía la cooperativa para adquirir o rehabilitar el inmueble-. Las cuotas comenzaron a emplearse como activos financieros e instrumentos de inversión para otros proyectos: los innmuebles y las cuotas cooperativas en los mismos funcionaban como una garantía de préstamos e inversiones.

La inflación del mercado de vivienda provocó que el precio de las acciones subiera hasta niveles desconocidos anteriormente ${ }^{66}$ y que la propiedad cooperativa pasase de ser un valor ilíquido y poseído colectivamente a un valor seguro y líquido para los miembros individuales ${ }^{67}$. Los desequilibrios surgieron cuando, tras la explosión de la burbuja, los bancos tasaron de nuevo las acciones individuales y les concedieron un valor muy inferior al de los años previos. Los miembros se encontraron irremediablemente atados a la cooperativa debido a las deudas contraídas y sin posibilidad real de vender dichas acciones por la inexistencia de personas interesadas en adquirirlas ${ }^{68}$. Creemos que estos problemas no deben desincentivar el recurso al modelo pero deben motivar que se aplique con algunas cautelas. Igualmente, es lógico que se fijen limitaciones a los socios cooperativos para vender sus acciones y que la cooperativa, a través de sus órganos democráticos, ejerza cierto control en este aspecto, para evitar que la especulación lacre a la cooperativa y la conduzca hacia la pérdida del bienestar de sus miembros.

Por otra parte, hay que hacer referencia a las incidencias asociadas a la cohabitación ya que, como han demostrado las experiencias prácticas en otros países, el sostenimiento conjunto de las estructuras y de los servicios compartidos genera fricciones y también puede convertirse en una carga económica pesada para los usuarios. Creemos que los inconvenientes de este tipo de comunidades pueden clasificarse en tres grupos. El primer conjunto surge como consecuencia inevitable del propio hecho de cohabitar y poner en común ciertos servicios. En segundo lugar, existe el riesgo de cerrar excesivamente la comunidad a ciertos tipos de usuarios y, como consecuencia, contribuir a una segregación social ${ }^{69}$. En tercer lugar, estas comunidades

66. Vid. BRUUN, M.H., op.cit., pp. 5-7.

67. Vid. GOTHAM, K.F.: "Creating liquidity out of spatial fixity: The secondary circuit of capital and the restructuring of the US Housing Finance System”. En: Subprime Cities: The Political Economy of Mortgage Markets (dir. AALBERS, M.B.), Wiley-Blackwell, Malden, 2012, pp. 25-52.

68. Vid. BRUUN, M.H., op.cit., pp. 11-13.

69. De hecho, en Estados Unidos, el senior cohousing se caracteriza por su elitismo ya que se exigen elevados umbrales de renta -normalmente vinculados a ciertos niveles de estudios- para ser usuario. Al contrario, en 
suelen presentar unos gastos de mantenimiento elevados y pueden generar un agotamiento económico para el titular del derecho de uso que, tras unos años, no es capaz de costear la renta necesaria para que la comunidad subsista. Este problema podría solucionarse o paliarse con subvenciones y ayudas de los gobiernos pero creemos que no debe ser la solución principal sino una medida de incentivo.

Finalmente, otros problemas que han observado algunos autores en relación a las iniciativas de cohousing internacionales son el fracaso de los modelos de cohabitación integrada, la falta de uniformidad en la forma jurídica adoptada y las dificultades para obtener la financiación necesaria para llevar a cabo el proyecto ${ }^{70}$. En relación al primero, se ha constatado que las comunidades que agrupan a habitantes de edades diferentes, han tenido más problemas para subsistir y se han disuelto en mayor número que las de senior cohousing ${ }^{71}$. El segundo no tendría por qué ser un problema ya que diferentes formas jurídicas podrían dar cabida a la cohabitación. Sin embargo, puede serlo cuando las comunidades carecen de toda forma legal y no tienen una cobertura normativa sólida. Finalmente, no muchas entidades bancarias están dispuestas a financiar iniciativas que parecen más inseguras que la tradicional construcción en régimen de propiedad horizontal. Las empresas más comprometidas con esta financiación pertenecen a la banca ética y son, en muchas ocasiones, cooperativas de crédito mientras que la mayoría de bancos suelen imponer cláusulas de propiedad horizontal que permitan poner en venta una parte de la propiedad, para el caso de que se deshaga la comunidad.

\section{Planes públicos de impulso de los nuevos modelos habitacionales}

A lo largo de este artículo hemos visto que la legislación existente puede dar cabida a nuevos modelos habitacionales basados en la comunidad y en la cesión del derecho de uso a los socios. Además, en España ya contamos con algunas comunidades de habitación que han recurrido a formas cooperativas para constituirse, cediendo un

otros países en los que el gobierno asume un papel regulador y financiador, la comunidad queda integrada por personas de estratos sociales inferiores y también puede convertirse en un gueto.

70. ETXEZARRETA ETXARRI, A., CANO FUENTES, G. \& MERINO HERNÁNDEZ, S.: "Las cooperativas de viviendas de cesión de uso: experiencias emergentes en España", CIRIEC-España, Revista de Economía Pública, Social y Cooperativa, no 92, 2018, pp. 11-23.

71. El estudio observó que en los proyectos intergeracionales hay más casos de abandono, tanto por motivos económicos -la inversión inicial es fuerte- como culturales - por la mentalidad arraigada en Espańa de ser propietarios de la vivienda-. 
derecho de uso a los socios. Pero, como es lógico, el éxito de estas experiencias no depende sólo de que la normativa no imponga obstáculos al fenómeno. Normalmente, por su carácter novedoso y por el cambio de mentalidad que suponen respecto a las formas de habitación tradicionales, requerirán que el gobierno y los poderes públicos promuevan acciones eficaces para darlos a conocer o apoyar económicamente alguna de sus fases.

En el fondo, dicho apoyo sería consecuencia del mandato constitucional recogido en el art. 47. No propugnamos -porque no nos parece conveniente- que deba ser la iniciativa pública la encargada de desarrollar los planes de promoción o que el Estado tenga un deber de aportar grandes subvenciones para la construcción o la participación en las comunidades. Sin embargo, sí es necesario facilitar de algún modo la fase de construcción de las viviendas ya que los socios fundadores que se hacen cargo de esta primera etapa pueden encontrarse sin incentivos suficientes para comenzar el proyecto. Y son precisamente los fundadores los que soportan los gastos iniciales y el peso de los trámites de constitución y de financiación de la cooperativa.

En este sentido, y aunque se trate de una iniciativa tímida, destacamos que el Estado parece haber percibido la conveniencia de la cesión de uso y ha creado un Programa 9 en el Plan Estatal de Vivienda de los ańos 2018 a 2021. El objetivo de dicho programa es conceder una ayuda económica a la promoción o rehabilitación de viviendas que se destinen, durante un plazo mínimo de cuarenta años, al alquiler o cesión de uso para personas mayores o con discapacidad, disponiendo de instalaciones y servicios comunes adaptados. La descripción de las ayudas puntualiza que los habitantes no adquieren la propiedad de la vivienda sino el disfrute temporal (alquiler o cesión de uso) y que las construcciones dispondrán de partes comunes y adaptadas - una de las características fundamentales del cohousing-.

En cuanto a los promotores que pueden beneficiarse de las ayudas, éstos son de dos tipos: el primero vinculado a la Administración Pública y el segundo integrado por fundaciones, empresas de economía social y sus asociaciones, cooperativas de autoconstrucción, ONG y asociaciones declaradas de utilidad pública. Por lo tanto, las cooperativas a las que nos hemos referido a lo largo de este artículo podrían obtener las ayudas vinculadas a este programa. Son requisitos necesarios para poder ser habitante que la persona sea mayor de 65 ańos o presente alguna discapacidad y que sus ingresos sean inferiores a 5 veces el IPREM y su patrimonio no superior a $200.000 €$, sin disponer, además, de una vivienda en propiedad ${ }^{72}$.

72. Para más información en este punto, puede consultarse la siguiente página web: https://www.fomento.gob.es/arquitectura-vivienda-y-suelo/programas-de-ayudas-a-la-vivienda/programapara-el-fomento-de-ciudades-sostenibles-y-competitivas 
Finalmente, consideramos que tanto las Comunidades Autónomas, a nivel regional, como los ayuntamientos, tienen un papel importante en estas iniciativas, dado que su contacto con las comunidades será más estrecho, sobre todo por parte de las concejalías de urbanismo de los últimos ${ }^{73}$. En este sentido, destacamos dos ejemplos. Por una parte, el ya comentado sobre el Ayuntamiento de Rivas Vaciamadrid, el cual ha cedido terrenos para la construcción de una comunidad de cohousing y asiste a los socios en el proceso de diseńo, a través de la Empresa Municipal de la Vivienda de Rivas. Esta participación normalmente implicará que, al cabo de un periodo de tiempo, los terrenos cedidos a la cooperativa pasarán a ser del municipio. Ahora bien, el Ayuntamiento podría renovar dicha cesión de uso o sacarla a concurso transcurrido el plazo inicialmente previsto - que es de 75 años en el caso comentado-.

Por su parte, en 2014, el Ayuntamiento de Atxondo, en el País Vasco, promovió la creación de cooperativas de construcción de viviendas en núcleos rurales, en las que el propio Ayuntamiento sería socio con el fin de destinar las viviendas que adquiriese por cesión al alquiler municipal. En la página de información de la construcción se estipulaba que los socios nunca serían propietarios pero podrían transmitir a sus descendientes su derecho de uso, si bien el alquiler de la vivienda sólo era posible para el Ayuntamiento y no para el resto de socios. Además, entre los requisitos que las personas beneficiarias debían cumplir se encontraban los siguientes: no ser propietario de otra vivienda, estar empadronado en Atxondo y no superar los ingresos establecidos por el Gobierno Vasco para la adjudicación de una $\mathrm{VPO}^{74}$.

\section{Conclusiones}

El objetivo de este artículo ha sido estudiar la conocida y antigua institución de las cooperativas de viviendas en relación a los novedosos modelos habitacionales caracterizados por la existencia de un matiz de comunidad entre los habitantes: la cesión de uso de las viviendas poseídas colectivamente y la cohabitación.

73. DROSTE ha destacado que las formas fundamentales de apoyo público a estas formas de construcción en común vienen de la mano de los entes locales, los cuales pueden actuar de tres formas: apoyar el concepto directamente, encargar los proyectos a entes externos o animar a inversores privados y propietarios a incluir, por ejemplo, iniciativas de cohousing en sus proyectos. Un alto grado de facilitación se consigue a través de subsidios y ayudas conjugadas para la construcción inicial y para los residentes, lo cual exige un apoyo interdepartamental (Vid. DROSTE, C.: "German co-housing: an oportunity for municipalities to foster socially inclusive urban development?”, Urban Research \& Practice, vol. 8(1), 2015, pp. 82-83).

74. Pueden consultarse los requisitos y otra información en la página web: http://www.atxondo.eus/es-ES/ Noticias/Documents/20140808_erderaz_kooperatibak_landaguneetan.pdf (pp. 7 y 8). 
Debemos partir de la situación actual. Por una parte, las cooperativas de viviendas se han visto afectadas por la crisis económica y financiera internacional, que repercutió especialmente en el sector inmobiliario. Por otra parte, no es correcto atribuir esta problemática al tipo social y muestra de ello es que otras sociedades se han visto igualmente perjudicadas. Además, hay que reconocer a las cooperativas sus posibilidades de adaptación de forma flexible a esa idea de colectividad presente en las nuevas figuras habitacionales, si bien es necesario desterrar en parte el empeño en ser propietario de la vivienda, en el sentido tradicional.

Un estudio de la legislación nacional y autonómica de cooperativas de viviendas realizado en este trabajo ha puesto de manifiesto la habitual finalidad de los socios de construir y disolver la cooperativa tras la adjudicación -más acentuada en algunas de esas normativas que en otras-. Frente a esta especie de regla general, nos encontramos con que la concesión de derechos distintos al dominio es la excepción. Sin embargo, actualmente observamos que la obtención de la propiedad no es el objetivo principal de los socios que constituyen cooperativas de viviendas para albergar comunidades de cesión de uso y/o de cohabitación -si bien esta última realidad podría también articularse a través de la adjudicación del dominio de los socios-.

Estas iniciativas, relativamente nuevas en nuestro país, son conocidas desde hace varias décadas en otros países de nuestro entorno, sobre todo en los escandinavos -a través del modelo Andel- y en Estados Unidos -donde triunfan las experiencias de senior cohousing-. En estos modelos de viviendas colectivamente poseídas es la sociedad la propietaria mientras que sus miembros obtienen un derecho de uso que puede ser vitalicio. Las normas para articular estas posibilidades no son muy abundantes ni detalladas y, por ello, el peso de la regulación recae sobre la autonomía de la voluntad de los constituyentes.

En realidad, la preponderancia de los pactos y normas establecidos por los miembros de cada cooperativa, manifestación de los acuerdos tomados por los órganos democráticos y reflejados en estatutos, reglamentos de régimen interno y ordenanzas, favorecen una mayor adaptación a los objetivos de esa particular comunidad. En este sentido, dado que nos podemos encontrar ante agrupaciones de personas que compartan servicios y zonas especialmente "sensibles" o problemáticas para la convivencia -cocina, comedor o gimnasio, entre otras-, la normativa deberá ser detallada en cuanto a los turnos de aprovechamiento y a las reglas de utilización y establecer mecanismos ágiles pero amistosos para resolver los posibles conflictos. En todo caso, los derechos de uso y usufructo, regulados en el CC, pueden servir como orientación sobre el contenido de los derechos y obligaciones de los habitantes de la cooperativa.

Los nuevos modelos de habitación poseen una importante carga social que puede ser calificada de filosofía teórica o de pura utopía pero no lo son, en dos sentidos. 
En primer lugar, no son irrealizables ya que en territorio español contamos con comunidades en régimen de cesión de uso y de cohabitación. En segundo lugar, no se trata de comunidades carentes de problemas, a pesar de la buena voluntad de sus miembros. Aparte de los conflictos asociados al hecho de convivir con un grado de comunidad mayor que el de una propiedad horizontal, algunos estudios han puesto de manifiesto la posible influencia de los intereses especulativos de los socios y de las entidades financieras, especialmente cuando pueden comerciar libremente con las cuotas de participación en periodos de expansión económica. Sin embargo, la constatación de estos riesgos no debe implicar descartar el modelo sino que ha de impulsarnos a establecer cautelas operativas -como limitaciones al arrendamiento y a la enajenación de las cuotas de uso - que permitan que la cooperativa perdure en el tiempo y busque el bien de la comunidad y no los intereses particulares de algunos agentes.

En cuanto a la viabilidad de estos modelos, no resultaría adecuado que fuese dependiente de las subvenciones del Estado. De hecho, en Dinamarca -país en el que surgió el modelo Andel- este tipo de habitación se ha asentado sobre la iniciativa privada, articulada a través de cooperativas. Sin embargo, es necesario cierto respaldo de las instituciones, sobre todo en lo que se refiere a la cesión de terrenos y a los incentivos proporcionados a los socios fundadores y promotores, que intervienen en la fase más arriesgada del proceso y en la que surgirán más eventualidades. Por ello, el apoyo de las instituciones públicas -de tipo económico, informativo y formativo- es un elemento importante.

Concluimos, por tanto, que el derecho a disfrutar de una vivienda digna, recogido en el art. 47 de nuestra Constitución y en otros textos internacionales, independientemente de su naturaleza jurídica y su consideración como derecho subjetivo o no, sigue siendo una de las necesidades humanas más esenciales. Se trata de un derecho que condiciona fuertemente otros como la intimidad personal y familiar y que influye en la ordenación del territorio ${ }^{75}$. Recientemente, la crisis del COVID-19 ha puesto de manifiesto la importancia psicológica y física que la posesión de un espacio digno y habitable tiene para toda persona. Por ello, promover el acceso de los ciudadanos a una vivienda digna ha de seguir siendo uno de los objetivos principales de los Estados. En esta búsqueda del bienestar social, creemos que las cooperativas de viviendas no han perdido su razón de ser. La filosofía de solidaridad que las ha

75. En este punto, algunos autores -destacando particularmente Henri Lefebvre a finales de la década de los 60 han hablado de un derecho a la ciudad (Vid. LEFEBVRE, H.: "Le droit à la ville", L'Homme et la société, no 6, 1967, pp. 29-35). Para un estudio completo de estas ideas también puede verse: MARCUSE, P.: “¿Qué derecho para qué ciudad en Lefebvre? / What right to what city in Lefebvre?", URBAN. Revista del Departamento de Urbanistica y Ordenación del Territorio, no 2, 2011, pp. 17-21. 
(pp. 167-206)

inspirado desde hace siglos las convierte en la forma social más adaptable a estos nuevos modelos habitacionales en los que subyace una fuerte idea de comunidad y de desarrollo sostenible del territorio y de la sociedad. 


\section{Bibliografía}

ADEVA CORTÉS, C.: "Análisis de la sentencia del TJUE de 3 de marzo de 2020 (C-125/2018) sobre las cláusulas IRPH de los contratos de préstamo hipotecario para la adquisición de vivienda", Noticias Jurídicas, 9 abril, 2020. Recuperado el 6 de julio de 2020, de: http://noticias.juridicas.com/conocimiento/articulosdoctrinales/15042-analisis-de-la-sentencia-del-tjue-de-3-de-marzo-de-2020-c125-2018-sobre-las-clausulas-irph-de-los-contratos-de-prestamo-hipotecario-para-la-adquisicion-de-vivienda/

AlBALADEJO, M.: Curso de Derecho Civil Español. Derecho de bienes, J.M. Bosch Editor, Barcelona, 1982.

BANHAM, R.: "A home is not a house". En: Housing and dwelling: Prespective on modern domestic architecture (dir. MILLER LANE, B.), Routledge, Nueva York, 2007, pp. 54-60.

BRESSON, S. \& DENÈFLE, S.: "Diversity of self-managed cohousing initiatives in France”, Urban Research \& Practice, vol. 8(1), 2015, pp. 5-16.

DOI: https://doi.org/10.1080/17535069.2015.1011423

BRUUN, M.H.: "The financialization of Danish cooperatives and the debasement of a collective housing good", Critique of Anthropology, vol. 38(2), junio, 2018, pp. 140-155. DOI: https://doi.org/10.1177\%2F0308275X18761960

CABRÉ ROMANS, E. \& ANDRÉS GALLART, A.: "Learning from each other: Catalonia meets Denmark", Housing Europe (EU blog), 16 junio, 2014. Recuperado el 11 de noviembre de 2019, de: https://www.housingeurope.eu/blog-291/ learning-from-each-other-catalonia-meets-denmark.

CALVO VÉRGEZ, J.: Las politicas monetarias del BCE ante la crisis económica, Dykinson, Madrid, 2019. DOI: https://doi.org/10.2307/j.ctvk8vzv3

DÍEZ-PICAZO, L. \& GULLÓN, A.: Sistema de Derecho Civil, vol. III (t. 2), Editorial Tecnos, Madrid, 2012.

DROSTE, C.: "German co-housing: an opportunity for municipalities to foster socially inclusive urban development?", Urban Research \& Practice, vol. 8(1), 2015, pp. 79-92. DOI: https://doi.org/10.1080/17535069.2015.1011428

DURANTE, C.: "Active citizenship in Italian cohousing: a preliminary reflection". En: Everyday Life in the Segmented City (eds. PERRONE, C., MANELLA, G. \& TRIPODI, L.), vol. 11, Emerald Group Publishing Limited, Bingley, 2011, pp. 307-333. DOI: https://doi.org/10.1108/S1047-0042(2011)0000011017 
ETXEZARRETA ETXARRI, A., CANO FUENTES, G. \& MERINO HERNÁNDEZ, S.: "Las cooperativas de viviendas de cesión de uso: experiencias emergentes en España", CIRIEC-España, Revista de Economía Pública, Social y Cooperati$v a, n^{\circ}$ 92, 2018, pp. 61-86. DOI: https://doi.org/10.7203/CIRIEC-E.92.9266

ETXEZARRETA ETXARRI, A. \& MERINO HERNÁNDEZ, S.: "Las cooperativas de vivienda como alternativa al problema de la vivienda en la actual crisis económica”, REVESCO. Revista de Estudios Cooperativos, no 113, 2014, pp. 92119. DOI: https://doi.org/10.5209/rev_REVE.2014.v113.43382

FERNÁNDEZ CARBALLO-CALERO, P.: "La adjudicación de la vivienda al socio". En: As Cooperativas de Vivendas no marco da Lei 5/1998 de Cooperativas de Galicia (dir. BOTANA AGRA, M.J. \& MILLÁN CALENTI, R.A.), Cecoop USC, Santiago de Compostela, 2007.

FERRANDO NICOLAU, E.: "El derecho a una vivienda digna y adecuada", Anuario de Filosofía del Derecho, no 9, 1992, pp. 305-324.

GALIANA SAURA, A.: "La vivienda como objeto de estudio desde el derecho: la vivienda como derecho humano y la cátedra UNESCO sobre vivienda", Hábitat y Sociedad, no 10, noviembre, 2017, pp. 129-144.

DOI: http://dx.doi.org/10.12795/HabitatySociedad.2017.i10.08

GOTHAM, K.F.: "Creating liquidity out of spatial fixity: The secondary circuit of capital and the restructuring of the US Housing Finance System". En: Subprime Cities: The Political Economy of Mortgage Markets (dir. AALBERS, M.B.), Wiley-Blackwell, Malden, 2012, pp. 25-52.

JARVIS, H.: "Saving space, sharing time: integrated infrastructures of daily life in cohousing", Environment and Planning A: Economy and Space, vol. 43(3), marzo, 2011, pp. 560-577. DOI: https://doi.org/10.1068/a43296

JIMÉNEZ CAMPO, J.: Derechos fundamentales: concepto y garantías, Editorial Trotta, Madrid, 1999.

LAMBEA RUEDA, A.: Cooperativas de Viviendas, Editorial Comares, Granada, 2007.

LAMBEA RUEDA, A.: "Cooperativas de viviendas en España: modelos de adjudicación”. En: VII Congreso Internacional RULESCOOP, 5 septiembre, 2012.

LEFEBVRE, H. : "Le droit à la ville”, L'Homme et la société, no 6, 1967, pp. 29-35. DOI : https://doi.org/10.3406/homso.1967.1063

LÓPEZ LETÓN, S.: "La burbuja que embriagó a España", Diario El País, 25 octubre, 2015. Recuperado de https://elpais.com/economia/2015/10/20/actualidad/1445359564_057964. html 
LÓPEZ RAMÓN, F.: "El derecho subjetivo a la vivienda", Revista Española de Derecho Constitucional, no 102, septiembre-diciembre, 2014, pp. 49-91.

LOUREDO CASADO, S.: "El 'senior cohousing' en España a través del recurso a las cooperativas de viviendas". En: Economía colaborativa y Derecho: aspectos civiles, mercantiles y laborales (dirs. CARRIL VÁZQUEZ, X.M., GARCÍA PÉREZ, R. \& LÓPEZ SUÁREZ, M.A.), Editorial Aranzadi, Cizur Menor, 2019, pp. 219-237.

MARCUSE, P.: “¿Qué derecho para qué ciudad en Lefebvre? / What right to what city in Lefebvre?”, URBAN. Revista del Departamento de Urbanistica y Ordenación del Territorio, no 2, septiembre, 2011, pp. 17-21.

MASLOW, A.H.: "Teoría de las Motivaciones Humanas", Psychological Review, no 50(4), 1943, pp. 370-396. DOI: https://doi.org/10.1037/h0054346

MCCAMANT, K. \& DURRETT, C.: Cohousing: A contemporary approach to housing ourselves, Ten Speed Press, Berkeley, 1989.

MERINO HERNÁNDEZ, S., "Cooperativas de viviendas". En: Tratado de Derecho de las Sociedades Cooperativas (dir. PEINADO GRACIA, J.I. \& coord. VÁZQUEZ RUANO, T.), vol. 2, Tirant lo Blanch, València, 2019, pp. 1393-1422.

MERINO HERNÁNDEZ, S.: "La cooperativa de viviendas como administradora de bienes comunes", Gizarte Ekonomiaren Euskal Aldizkaria/Revista Vasca de Economía Social, no 9, 2013, pp. 101-110.

MILÁ RAFEL, R.: Promoción inmobiliaria, Autopromoción y Cooperativas de Viviendas, Editorial Aranzadi, Cizur Menor, 2014.

OLIVER, P.: Built to meet needs: Cultural issues in vernacular architecture, Architectural Press, Oxford, 2006.

OTXOA-ERRARTE GOIKOETXEA, R.: "Reforma del régimen de las cooperativas de viviendas en Euskadi: de la promoción especulativa encubierta a la cooperativa con cesión de uso". En: XVI Congreso de Investigadores en Economía Social y Cooperativa, 19-21 de octubre 2016, CIRIEC-España, València.

PERENA VICENTE, M.: La constitución voluntaria del usufructo, Dykinson, Madrid, 2005.

RING, K.: "Reinventing density: how baugruppen are pioneering the self-made city", The Conversation, 22 noviembre, 2016. Recuperado el 6 de julio de 2020, de: https://theconversation.com/reinventing-density-how-baugruppen-are-pioneering-the-self-made-city- 66488

RUIZ VADILLO, E.: Introducción al estudio teórico-práctico del Derecho Civil, Editorial Ochoa, Logroño, 1984. 
TRUjILLO RINCÓN, M.A.: “Artículo 47”. En: Comentario a la Constitución Española (dirs. PÉREZ TREMPS, P.; SAIZ ARNAIZ, A. \& coord. MONTESINOS PADILLA, C.), vol. 1 (t. 1), Tirant Lo Blanch, València, 2018.

VILLANUEVA TURNES, A.: "Aproximación a la configuración jurídica del derecho a la vivienda dentro del ordenamiento jurídico español", Opinión Jurídica, vol. 14(28), julio-diciembre, 2015, pp. 79-90.

WAHBA, M.A. \& BRIDWELL, L.G.: "Maslow reconsidered: A review of research on the Need Hierarchy Theory", Organizational Behavior and Human Performance, vol. 15(2), abril, 1976, pp. 212-240.

DOI: https://doi.org/10.1016/0030-5073(76)90038-6

ZAVEI, S.J.A.P. \& JUSAN, M.M.: "Exploring Housing Attributes Selection based on Maslow's Hierarchy of Needs", Procedia - Social and Behavioral Sciences, vol. 42, 2012, pp. 311-319. DOI: https://doi.org/10.1016/j.sbspro.2012.04.195 